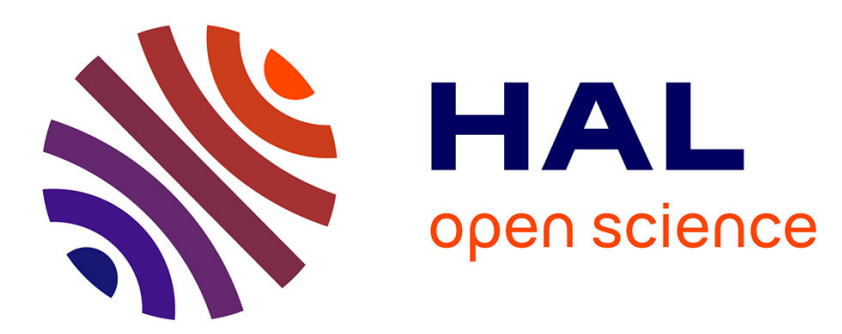

\title{
Multidisciplinary conceptual design optimization of aircraft using a sound-matching-based objective function
}

\author{
Matteo Diez, Umberto Iemma
}

\section{To cite this version:}

Matteo Diez, Umberto Iemma. Multidisciplinary conceptual design optimization of aircraft using a sound-matching-based objective function. Engineering Optimization, 2011, pp.1. 10.1080/0305215X.2011.591791 . hal-00735546

\section{HAL Id: hal-00735546 \\ https://hal.science/hal-00735546}

Submitted on 26 Sep 2012

HAL is a multi-disciplinary open access archive for the deposit and dissemination of scientific research documents, whether they are published or not. The documents may come from teaching and research institutions in France or abroad, or from public or private research centers.
L'archive ouverte pluridisciplinaire HAL, est destinée au dépôt et à la diffusion de documents scientifiques de niveau recherche, publiés ou non, émanant des établissements d'enseignement et de recherche français ou étrangers, des laboratoires publics ou privés. 


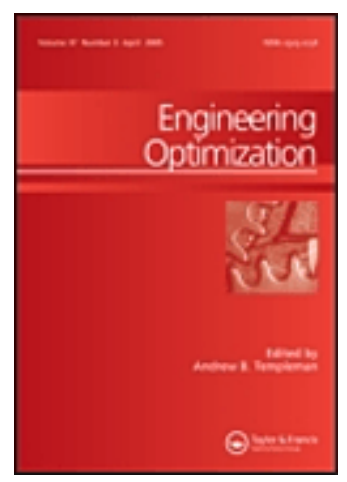

\section{Multidisciplinary conceptual design optimization of aircraft using a sound-matching-based objective function}

\begin{tabular}{|r|l|}
\hline Journal: & Engineering Optimization \\
\hline Manuscript ID: & GENO-2010-0225.R4 \\
\hline Manuscript Type: & Original Article \\
\hline Date Submitted by the \\
Author: & 10 -May-2011 \\
\hline Keywords: & $\begin{array}{l}\text { Multidisciplinary conceptual design optimization (MCDO) of aircraft, } \\
\text { sound-matching based ob jective function, European Research Pro } \\
\text { ject SEFA (Sound Engineering For Aircraft) }\end{array}$ \\
\hline & $\begin{array}{l}\text { Diez, Matteo; Roma Tre University, Mechanical and Industrial } \\
\text { Engineering Dept. } \\
\text { Engineering Dept. }\end{array}$ \\
\hline
\end{tabular}

\section{SCHOLARONE ${ }^{m}$ Manuscripts}




\title{
RESEARCH ARTICLE
}

\section{Multidisciplinary conceptual design optimization of aircraft using a sound-matching-based objective function}

\author{
Matteo Diez and Umberto Iemma \\ Dipartimento di Ingegneria Meccanica e Industriale \\ Università degli Studi "Roma Tre" \\ Via della Vasca Navale 79, 00146, Rome, Italy \\ (Received 00 Month 200x; final version received 00 Month 200x)
}

\begin{abstract}
The paper presents a novel approach to include community noise considerations based on sound quality in Multidisciplinary Conceptual Design Optimization (MCDO) of civil transportation aircraft. The novelty stems from the use of an unconventional objective function, defined as a measure of the difference between the noise emission of the aircraft under analysis and a reference "weakly annoying" noise, the target sound. The minimization of such a merit factor yields an aircraft concept with a noise signature as close as possible to the given target. The reference sound is one of the outcomes of the European Research Project SEFA (Sound Engineering For Aircraft, VI Framework Programme, 2004-2007), and used here as an external input. The aim of the present work is to address the definition ad the inclusion of the sound-matching-based objective function in the MCDO of aircraft.
\end{abstract}

Keywords: Multidisciplinary conceptual design optimization (MCDO) of aircraft; sound-matching based objective function; European Research Project SEFA (Sound Engineering For Aircraft).

Email: m.diez@uniroma3.it, m.diez@insean.it (M. Diez); u.iemma@uniroma3.it (U. Iemma, corresponding author)

URL: http:/mc.manuscriptcentral.com/geno Email: A.B.Templeman@liverpool.ac.uk 


\section{Introduction}

The methodology presented in this paper represents a novel approach to include community noise considerations based on sound quality in the Multidisciplinary Conceptual Design Optimization (MCDO) of commercial aircraft. The novelty stems from the use of an unconventional objective function (at least in the aeronautical community), capable to measure the difference between the noise produced by the aircraft configuration under analysis and a reference "weakly annoying" noise, the target sound. The minimization of such a merit factor yields a "sound-matching" optimization criterion, which provides the aeronautical designer with an additional tool to reduce the impact of the civil aviation on the residential community. The present work should be interpreted by the reader as an assessment of the methodology for the inclusion of such a novel requirement in MCDO of aircraft, and not as a proposal for new aircraft configurations.

The present approach was first explored within the European research project SEFA (Sound Engineering For Aircraft). The project started in 2004 within the framework of the X-Noise Thematic Network. The purpose of the project was to investigate the inclusion of sound quality requirements (besides classical noise level constraints) in the aircraft design process, since the initial conceptual phase. The core team of the project consortium was constituted by psychoacoustics experts, sound engineers, aircraft designers and manufacturers; the role of the authors in that context was to provide a methodology to convert sound quality requirements into aircraft design. In other words, the authors were responsible for the "translation" of the recommendations resulting from the psychometric tests campaign into design requirements. The target sounds used in the present work are one of the outcomes of the project and are characterized by a low level of annoyance. They are chosen among a number of synthesized aircraft sounds normalized to the same EPNL (Effective Perceived Noise Level) - being the focus on sound quality rather than on noise level.

It is worth pointing out that the novelty of the present work is not the inclusion of community noise considerations in the MCDO of aircraft. The inclusion of environmental sustainability issues in the MCDO process has been explored by a number of authors in literature. Community noise considerations based on sound level may be found in a number of multidisciplinary design optimization work (Caves et al. 1997, 1998, Manneville et al. 2001, Hill 2004). An additional example in this direction is given by Antoine and Kroo (2004), and Antoine et al. (2004), where a trade-off between aircraft performance, engine exhaust emission and community noise is detailed. Moreover, Hosder et al. (2004) and Leifsson et al. (2006) concentrate on the reduction of the noise level produced by the the airframe. Community noise issues have been also included in aircraft life-cycle-costs optimization (e.g., Iemma and Diez 2006) and considered in the context of robust design of aircraft (see, e.g., Ilyin et al. 2004, and Diez and Iemma 2006).

With respect to the state of the art, the present approach provides the designer with an effective alternative, assessing the "qualitative" aspect of the noise and thus offering an additional degree of freedom for the alleviation of the acoustic impact of the civil aviation. An exhaustive report of the activities conducted within the SEFA project can be found in Schutte et al. (2006), Bisping (2005), Bisping et al. (2006), Mueller and Schutte (2006), Barbot et al. (2008), and Janssens et al. (2005). It is worth noting that this paper doesn't deal with the assessment of the aircraft noise quality, nor with the estimate of the level of annoyance produced by the civil aviation, nor with the definition of the target sounds, used in the present work as external inputs. The focus of the paper is the definition and assessment of the sound-matching-based MCDO algorithm, 
required to relate the sound-quality assessment (i.e., the target sound) with the aircraft design and manufacturing. Specifically, an objective function based on the measure of the difference between the current aircraft noise and the target sound is introduced in the aircraft conceptual design optimization. This measure is defined as the $L^{p}$-norm of the difference between the two time-dependent spectra (spectrograms), integrated over the entire duration of the acoustic event.

The use of this norm may be considered as a standard approach to measure the difference between two functions. The use of the $L^{p}$-norm as the merit factor of an optimization procedure can be found in several research fields, such as optical pattern recognition, digital signal processing, computer graphics, computer aided diagnostic (among many others). Moreover, in the aeronautical field, the normed vector spaces are used to verify the convergence of numerical solutions, in order to assess computer simulations. This is commonly done, for example, to assess the reliability and usability of computational fluid dynamics (see, e.g., Brentner and Farassat 1998) or finite element structural (see, e.g., Zienkiewicz and Taylor 2000, or Babuska and Strouboulis 2001) models. Also, the normed vector spaces are used in inverse aerodynamic shape design (see, e.g., Soemarwoto 1998). Nevertheless, applications with a direct, clear relationship with the approach used here for noise annoyance alleviation are not present in literature (at least in the aircraft design field).

The paper is organized as follows. Section 2 presents the approach explored in the SEFA project to cope with sound quality issues within the aircraft design process. In Section 3 the key aspect of the present work is presented and the objective function used to drive the optimization towards the desired sound quality requirement is given. Specifically the sounds difference $\Delta_{p}$ is defined, and its use as an objective function in the MCDO process is outlined. Section 4 discusses the role of the aeroacoustics and its interaction with the flight mechanics, whereas in Section 6 numerical results of a preliminary campaign of computer simulations are presented and commented. It is worth noting that the numerical tests presented in this work have to be intended as an assessment of the sounds matching procedure and not as a proposal for new aircraft configurations. Finally, the Appendix A shows an overview on the multidisciplinary analysis environment used, in terms of description of the simulation models and definitions of their mutual relations.

\section{Sound quality as an optimization objective: the target sound}

The idea on the basis of the present work stems from specific issues raised by the aircraft manufacturers within the context of the VI European research framework program. The questions were (in extreme synthesis): It is possible to abate the aircraft noise impact on the population, not only by reducing the sound level, but also by improving the "quality" of the noise (whatever it could mean)? And, if so, how can "sound quality" be included among the design requirements since the very early conceptual phase? The intrinsic difficulty of the problem is twofold: $i$ ) sound quality is by itself a concept which is difficult to "quantify"; ii) even when appropriate sound quality descriptors are introduced, their relation with the physics underlying the sound generation and propagation phenomena is not direct, and often unclear. As a consequence, the design recommendations and constraints required to achieve a "sound quality improvement" cannot be easily derived. How should a turbofan engine be modified to make its noise less "rough," or "sharper," or "not booming"? Here, the direct use of sound-quality-related parameters in the design optimization procedure is avoided, and the sound quality improvement is indirectly 


\section{Sound quality as an optimization objective: difference between two sounds}

This section presents the key point of the present paper, i.e., the definition of the objective function more appropriate to handle the sound quality requirements. Starting from the basic idea of the work, i.e., that the quality of the aircraft noise can be improved by minimizing the difference from a "weakly annoying" target, one may define the objective function as a suitable measure of this difference.

The noise reaching a listener, during a specific flight operation, may be characterized by a time-varying spectrum, and can be effectively described by its spectrogram. ${ }^{1}$ The latter provides the overall picture of the amplitude of the acoustic event, in the timefrequency plane. Figure 1 depicts the spectrograms of two re-synthesized aircraft noises. The first one is the reproduction of a recorded sound, used to assess the synthesis technique adopted in the SEFA project, whereas the second is the target obtained from the first by reducing by $8 d B$ the two highest tones.

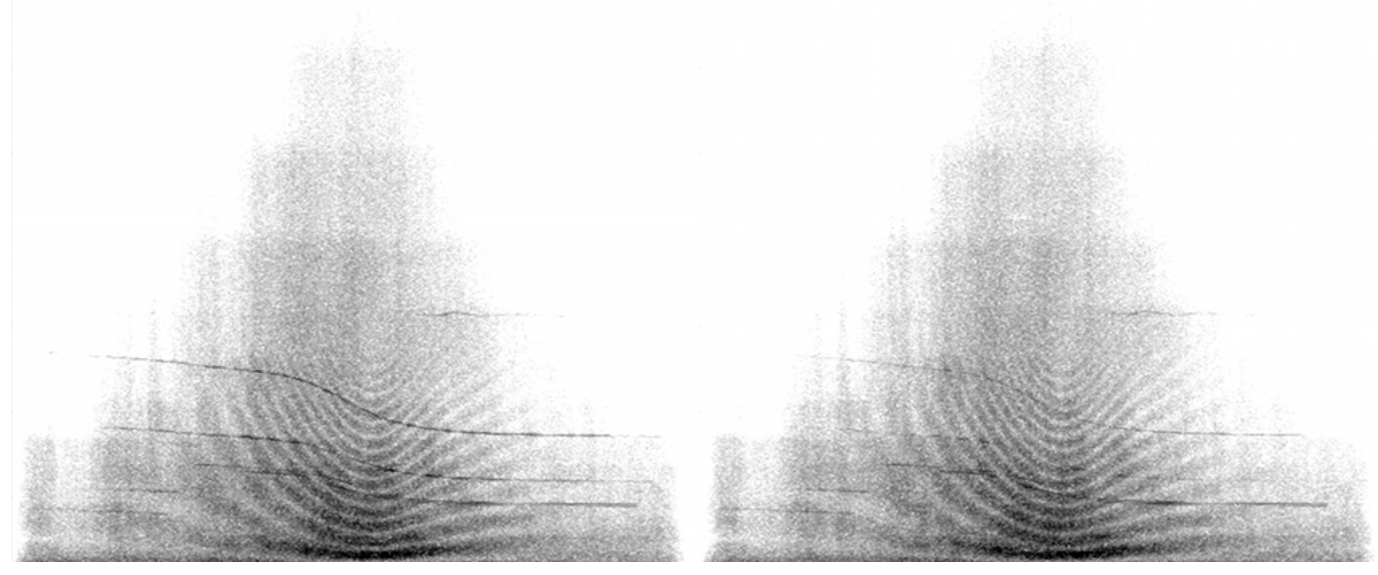

Figure 1. Target spectrograms no. 1 and 2. Medium-range, twin-engines aircraft during approach.

A simple way to measure the difference between the current noise and the target sound

\footnotetext{
${ }^{1}$ Within the framework of the present work, based on an amplitude comparison, the lack of information about the phase is not a limitation.
} 
is the evaluation of the integral

$$
\mathcal{I}=\frac{1}{T} \frac{1}{F} \int_{0}^{T} \int_{f_{\min }}^{f_{\max }}\left|S_{c}(f, t)-S_{t}(f, t)\right| d f d t
$$

where $S_{c}(f, t)$ is the time-dependent spectrum (spectrogram) of the noise under analysis, whereas $S_{t}(f, t)$ is that of the target, and $F=f_{\max }-f_{\min }$. Unfortunately, this approach might be misleading in our kind of application. Local differences, caused by missing or misplaced tones, ${ }^{1}$ have a small contribution to the value of $\mathcal{I}$ but, from the perceptive point of view, can be very important.

The latter point can be explained with a simple example. Consider the three functions depicted in Figure 2, and assume the black solid curve, $f_{A}$, as the reference (target). The three functions are defined in the domain $[a, b]$ by the equations

$$
\begin{aligned}
& f_{A}(x)=\alpha_{A} x^{2}+\beta_{A} \\
& f_{B}(x)=\alpha_{B} x^{2}+\beta_{B} \\
& f_{C}(x)=f_{A}(x)+\Gamma \pi \epsilon \delta_{\epsilon}(x-c)
\end{aligned}
$$

where $\delta_{\epsilon}(x-c)=\epsilon / \pi\left[(x-c)^{2}+\epsilon^{2}\right]$ represents a peak in $x=c$ of amplitude equal to $\delta_{\epsilon}(0)=1 / \pi \epsilon$. Note that the limit of $\delta_{\epsilon}(x-c)$ as $\epsilon \rightarrow 0$ is the Dirac delta function $\delta(x-c)$ in $c$.

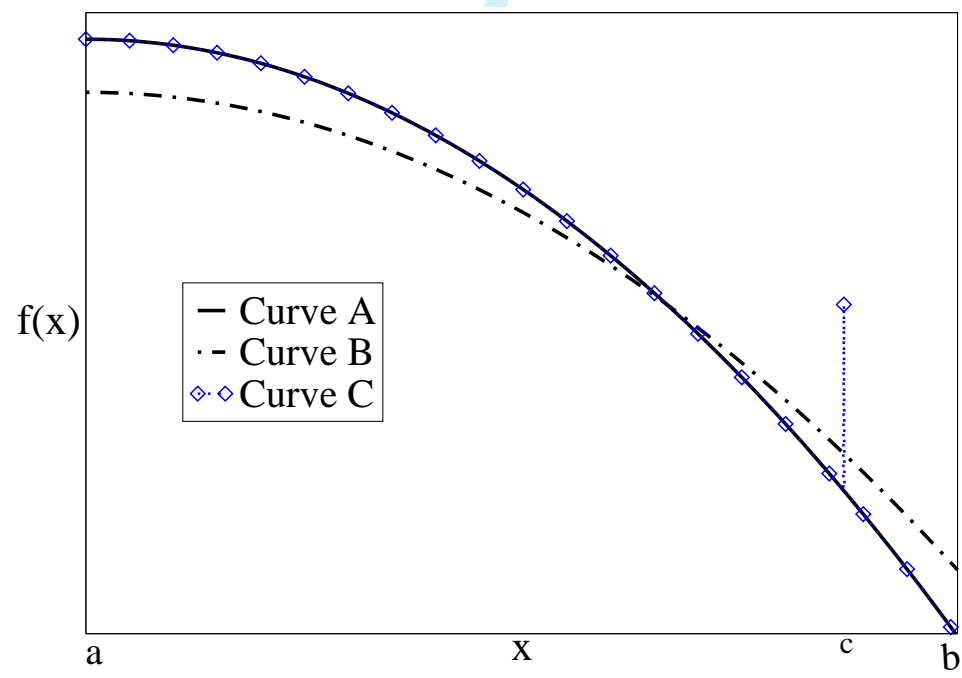

Figure 2. Test functions.

As can be clearly seen from the picture, the second curve differs from the first one along the whole interval $[a, b]$ (provided, of course, that $\alpha_{A} \neq \alpha_{B}$ and $\beta_{A} \neq \beta_{B}$ ), whereas the third coincides with the reference, except for the presence of a peak in $c$ of amplitude $\Gamma$. The absolute value of the differences between the first test function and the reference, $\left|f_{A}-f_{B}\right|$, over the interval $[a, b]$ has a finite, positive value, whereas the difference with

1 "Misplaced" tones refer to harmonics which are slightly shifted in one of the two sounds, but which can be still recognized as produced by the same source. 
the second, $\left|f_{A}-f_{C}\right|$, clearly integrates to zero as $\epsilon \rightarrow 0$. When applying the simple definition for the difference given by Eq. 1 to the present example, ${ }^{2} f_{C}$ would appear to have almost zero difference from $f_{A}$, and so ranked as the "closest." This is a reasonable result when using the metric introduced with Eq. 1.

The interpretation of the latter example within the framework of the present application leads to a different result. Assuming the three functions as spectral representations of three steady noises, $f_{A}$ and $f_{B}$ represent two broadband spectra parabolically decreasing at high frequencies, whereas the function $f_{C}$ exhibits a pure tone at frequency $c$, superimposed to the same broadband content of $f_{A}$. Despite the overall difference between their spectra, the noises associated to $f_{A}$ and $f_{B}$ would sound as extremely similar (probably almost identical). Conversely, the presence of the tonal component in the spectrum $f_{C}$ would make the corresponding sound clearly distinguishable from the others, even to totally untrained ears. Hence, an appropriate measure of the difference between sounds should be capable to assess local differences due to prominent harmonics.

To this aim, the $L^{p}$-norm is introduced in the present context. Consider, then, the spectrograms space as a vector space of $p$-power integrable functions associated with the norm (normalized with respect to the measure $\mu(\mathcal{D})$ of the domain $\mathcal{D}$ )

$$
\|g\|_{p}:=\left[\frac{1}{\mu(\mathcal{D})} \iint_{\mathcal{D}}|g|^{p} d \mathcal{D}\right]^{\frac{1}{p}}, \quad p=1, \ldots, \infty
$$

Such a vector space belongs to a class of Banach spaces of particular interest in physics and engineering applications: the $L^{p}$-spaces (see e.g., Royden 1969). The $L^{p}$-norm satisfies

\footnotetext{
${ }^{2}$ It reads
}

$$
\mathcal{I}=\frac{1}{b-a} \int_{a}^{b}\left|f_{A}-f_{X}\right| d x
$$




$$
\|g\|_{\infty}:=\lim _{p \rightarrow \infty}\|g\|_{p}=\lim _{p \rightarrow \infty}\left[\frac{1}{\mu(\mathcal{D})} \iint_{\mathcal{D}}|g|^{p} d \mathcal{D}\right]^{\frac{1}{p}}=\max \{|g|\}
$$

This property is very useful to define the desired measure of the difference between two sounds. ${ }^{1}$ Specifically, consider two arbitrary functions $g$ and $h$, the value of the integral

$$
\|g-h\|_{p}=\left[\frac{1}{\mu(\mathcal{D})} \iint_{\mathcal{D}}|g-h|^{p} d \mathcal{D}\right]^{\frac{1}{p}}
$$

depends on the value of $p$. In other words, the difference between two functions, as results from Eq. 7, depends on the order of the space where the measure is taken. Specifically, low values of $p$ enhance the contribution of distributed (or broadband, if we consider spectra) differences, whereas high values emphasize local differences (or tonal, considering spectra). In the limit for $p \rightarrow \infty$, even differences pertaining to zero-measure sub-domains can be evaluated. Therefore, we may state that the $L^{p}$-norm is able to assess tonal or broadband differences when comparing sounds, and appears to be a good candidate to cover the role of the objective function in our optimization problem.

Hence, we define the difference $\Delta_{p}$ between current and target sounds as

$$
\Delta_{p}:=\left\|S_{c}-S_{t}\right\|_{p}=\left[\frac{1}{T} \frac{1}{F} \int_{0}^{T} \int_{f_{\min }}^{f_{\max }}\left|S_{c}(f, t)-S_{t}(f, t)\right|^{p} d f d t\right]^{\frac{1}{p}}
$$

where $F=f_{\max }-f_{\min }$. Clearly, $\Delta_{1}=\mathcal{I}$ is the volume bounded by the two spectrograms (normalized with respect to the measure of the domain, $T F$ ), whereas $\Delta_{\infty}$ represents the maximum value of their point-wise difference in the time-frequency plane. Through an appropriate choice of $p$, one may emphasize broadband or tonal differences, and tune the measure to the specific application at hand.

To better explain this point, the above definition of the difference $\Delta_{p}$ (Eq. 8) is applied to the analytical test problem presented above. ${ }^{2}$ The $L^{p}$-norm for the test functions differences is plotted in Figure 3 as a function of $p$ (with $\alpha_{A}=-1, \beta_{A}=2, \alpha_{B}=-0.8$, $\beta_{B}=1.8, c=1.304, \Gamma=1.0$, and $\left.\epsilon=10^{-6}\right)$. The value of $\left\|f_{A}-f_{B}\right\|_{p}$ is not zero for all $p$, varying from the value of the area bounded by the two functions, $\Delta_{1}$, to the asymptotic limit $\Delta_{\infty}=\max \left(\left|f_{A}-f_{B}\right|\right)=0.249$. On the contrary, the difference from the reference of the function $f_{C}$ is very close to zero for $p=1$, according to the fact that the area bounded by $f_{A}(x)$ and $f_{C}(x)$ has zero measure for $\epsilon \rightarrow 0$, and increases with $p$ (giving more emphasis to the local difference), tending to the limit $\Delta_{\infty}=\Gamma-f_{A}(c)=0.7$.

\footnotetext{
${ }^{1}$ It is worth noting that the normalization with respect to the measure of the domain $\mu(\mathcal{D})$ (not present in the standard definition of the $L^{p}$-norm) does not modify the asymptotic behavior of the norm, since

$$
\lim _{p \rightarrow \infty} \sqrt[p]{a}=1, \quad \forall a
$$

${ }^{2}$ It reads
}

$$
\Delta_{p}=\left[\frac{1}{b-a} \int_{a}^{b}\left|f_{A}-f_{X}\right|^{p} d x\right]^{\frac{1}{p}}
$$


Accordingly, the difference $\Delta_{p}$ can be included in the aggregate objective function $(\mathrm{AOF})$, along with the other merit factors that are of interest in the optimization process. A typical AOF has the form

$$
\operatorname{OBJ}(\mathbf{x}):=\sum_{k=1}^{n} w_{k} \Psi_{k}(\mathbf{x})+w_{\Delta} \Delta_{p}(\mathbf{x})
$$

where $\mathbf{x}$ is the variables vector (collecting design and operational parameters), and the $\Psi_{k}$ are the merit factors for the MCDO, related to quantities such as empty weight, fuel burn, payload, or manufacturing and management costs. The weights $w_{k}$ and $w_{\Delta}$ are chosen to balance the relative influence of each factor on the optimization procedure.

In order to assess the effectiveness of the present approach in driving the optimization towards the desired matching to the target, $w_{k}=0, \forall k$, and $w_{\Delta}=1$ will be used for the numerical results.

\section{Flight mechanics and aeroacoustics: the interplay}

As apparent, the estimate of the noise emissions within the MCDO requires the introduction of suitable aeroacoustic models. The role of these aeroacoustic predictors, and their deep interaction with the flight mechanics deserve a careful discussion. In a conceptual design optimization aimed at aircraft performances, the optimality criteria (such as minimum fuel consumption, maximum range or payload, etc.) are typically related to the whole mission. Thus, the most relevant operating condition is the cruise, being the effects of the initial and final phases of the flight negligible in that context. Conversely, the flight phases and procedures more annoying for the residential community are, apparently, take-off and landing, when the aircraft is close to the ground. During these mission segments, the acoustic impact of the aircraft deeply depends on its operating conditions, thus requiring the use of simulation tools capable to evaluate the aircraft mechanics as a function of the relevant operational parameters involved. Specifically:

- the tonal and broadband components emitted by the sources related to the propulsion system (fan, compressor, turbine, buzz-saw, jet) depend on the engines setting, which depends on the thrust required;

- a significant portion of the airframe noise is proportional to the deployment of the high lift devices (flaps and slats), which depends on the lift coefficient required;

- being several of the acoustic sources characterized by a strong directivity, the attitude of the aircraft deeply influences the spectrum that reaches a listener on the ground;

- the relative speed and the distance between the aircraft and the listener influence the spectrum of the received signal, through atmospheric and Doppler effects.

Therefore, a congruent prediction of the aircraft noise needs a congruent modeling of the flight mechanics.

\section{1. $\quad$ Flight mechanics}

The global aerodynamic loads acting on the aircraft are evaluated via BEM (see Appendix A), and the total mass distribution is determined, so as to locate the centre of mass, $G$. The equilibrium of the forces in the vertical plane is imposed by taking into account: a) the lift and the drag of the wing and the tail, $b$ ) the drag of the fuselage $c$ ) the 


\subsection{Noise prediction}

Once the flight configuration and parameters are properly identified, the prediction of the noise perceived at a specified location requires the modeling of the physical phenomena involved in the sound generation and propagation mechanisms. In the optimization context, the identification of a proper trade-off between accuracy and computational cost is a key aspect. Within the SEFA project, the choice of the noise models fell onto the well-assessed, widely used, and computationally not expensive models able to predict the aircraft noise spectra at specified locations. Specifically, Fink's model (Fink 1977) is used to compute the airframe noise, and Heidmann's method (Heidmann 1975) is applied for the fan and compressor noise. The jet noise is estimated from a database of recorded data (Olsen and Friedman 1974) and the buzz-saw noise is calculated following Morfey and Fisher (1970). Atmospheric attenuation (Sutherland et al. 1974), ground reflection (Attenborough 1992) and doppler effect (e.g., Ruijgrok 2000) are also taken into account. It has to be noted that in this preliminary assessment of the method, the engine parameters involved in the noise prediction are not completely joined to those used for the propulsion model, which, at the present stage of the work, is a simple Thrust-Mach no.-RPM relation (see Appendix A). The extension of the latter model to join the aeroacoustic parameters will be addressed in future work.

\section{Formulation of the optimization problem}

In this section the overall MCDO problem is formulated in its standard form. Generally, an MCDO problem may assumed as a constrained minimization problem as follows

$$
\begin{aligned}
& \text { minimize } O B J(\mathbf{x}), \quad \mathbf{x} \in A \\
& \text { subject to } g_{n}(\mathbf{x}) \leq 0, \quad n=1, \ldots, N \\
& \text { and to } h_{m}(\mathbf{x})=0, \quad m=1, \ldots, M
\end{aligned}
$$

where $\mathbf{x}$ is the design (and operational) parameters vector and $O B J(\mathbf{x})$ is the optimization objective; the $g_{n}$ are $N$ inequality constraints, whereas the $h_{m}$ are $M$ equality constraints. Note that generally, in the multidisciplinary context, the objective, $O B J$, and the constraints, $g_{n}$ and $g_{m}$, are assessed through a fully coupled multidisciplinary analysis and are consistent with all the disciplines involved. The design parameters used in the present work are summarized in Tables 1 and 2 . In the present formulation, the 
objective is expressed by Eq. 9, whereas the inequality constraints are defined as

$$
\begin{aligned}
& g_{1}(\mathbf{x}):=\sigma(\mathbf{x}) / \sigma_{\max }-1 \leq 0 \\
& g_{2}(\mathbf{x}):=\tau(\mathbf{x}) / \tau_{\max }-1 \leq 0 \\
& g_{3}(\mathbf{x}):=U_{f, \min } / U_{f}(\mathbf{x})-1 \leq 0 \\
& g_{4}(\mathbf{x}):=U_{d, \min } / U_{d}(\mathbf{x})-1 \leq 0 \\
& g_{5}(\mathbf{x}):=C_{M, \alpha} \leq 0
\end{aligned}
$$

where $\sigma$ is the normal stress arising in the structure, $\tau$ is the shear stress and $U_{f}$ and $U_{d}$ are the flutter and divergence speed respectively; $\sigma_{\max }, \tau_{\max }, U_{f, \min }$, and $U_{d, \min }$ are the relative critical values. $C_{M, \alpha}$ is the derivative of the total moment coefficient with respect to the angle of attack $\alpha$. The equality constraints assumed in the optimization process are related to the static equilibrium of the aircraft in the vertical plane:

$$
\begin{aligned}
h_{1}(\mathbf{x}) & :=F_{x}=0 \\
h_{2}(\mathbf{x}) & :=F_{z}=0 \\
h_{3}(\mathbf{x}) & :=M_{G, y}=0
\end{aligned}
$$

where $F_{x}$ and $F_{z}$ are the projections on the $x$ and $z$ axis of the total force acting on the aircraft and $M_{G, y}$ is the projection on the $y$ axis of the total moment evaluated with respect to the centre of mass $G$.

\section{Numerical results}

In this section, preliminary numerical results are presented. As mentioned in Section 4 (see also Appendix A), the propulsion system is assessed here by means of a simple semiempirical model based on available data (Thrust-Mach no.-RPM relation). Although a detailed model for the thermodynamics of the propulsion would be highly desirable, in order to properly relate the operating conditions of the engines with the thrust, the benchmarks performed so far (see Iemma et al. 2006a, Iemma et al. 2006b, and Diez et al. 2007) reveal that the method is mature enough to address a preliminary design exercise.

It is essential noting that, in order to assess the methodology for sound matching, the objective function considered in the following consists only in the $L^{p}$-difference between the current spectrogram and the given target $\left(w_{k}=0, \forall k\right.$, and $w_{\Delta}=1$, see Eq. 9 , with $p=2$ ). The reader should then interpret the following results as an assessment of the sounds matching procedure and not as a proposal for environmentally friendly or "not annoying" real aircraft configurations.

The case study is defined in terms of aircraft type, flight procedure, and target sounds to match. The aircraft design specifications are summarized in Tables 3 and 4 . Note that some of the relevant design requirements commonly used in MCDO such maximum range, maximum cruise speed and altitude are not included since, as mentioned, the present optimization exercises take into account only the sounds matching criterion. The target sounds are chosen among the set of sounds produced within the SEFA project and are related to the landing procedure of an aircraft of the same category as that defined 
by the values in Tables 3 and 4 . The sounds chosen as targets for the optimization benchmark are represented by the spectrograms depicted in Figures 1 and 2 .

The two spectrograms are converted into a set of third-octave band spectra (one for each time slot chosen for the analysis), to make them compatible with the output of the noise models. The integral of Eq. 8 is numerically evaluated by computing the thirdoctave band levels in the frequency range of interest and adopting a Gauss-Legendre quadrature rule in the time domain, i.e.,

$$
\begin{aligned}
\Delta_{p} & =\left[\frac{1}{T} \frac{1}{F} \int_{0}^{T} \int_{f_{\min }}^{f_{\max }} \Delta S^{p}(t, f) d f d t\right]^{\frac{1}{p}} \\
& =\left[\frac{1}{2 F} \int_{-1}^{1} \int_{f_{\min }}^{f_{\max }} \Delta S^{p}(\tau, f) d f d \tau\right]^{\frac{1}{p}} \simeq\left[\frac{1}{2 F} \sum_{k=1}^{N_{G}} \sum_{j=1}^{N_{F}} W_{k} \Delta S^{p}\left(\tau_{k}, f_{j}\right) F_{j}\right]^{\frac{1}{p}}
\end{aligned}
$$

where $\tau=2 t / T-1, N_{G}$ is the number of Gaussian abscissa used for the quadrature, $N_{F}$ is the number of third-octave bands in the frequency range of interest, and $F_{j}$ and $f_{j}$ are the amplitude and the central frequency of the $j^{\text {th }}$ third-octave band, respectively.

Two different set of variables are chosen for the optimization problem. The first includes procedural variables, propulsion-related variables, and high-lift devices design variables. The second set of variables is enriched by the design variables of the main wing. The two sets are shown in Tables 1 and 2, and will be addressed in the following as set number 1 and 2, respectively.

Finally, an evolutionary algorithm (e.g., Goldberg 1989), coupled with a linear penalty function method (see Appendix B) is chosen to solve the constrained minimization problem. Specifically, the real coded FORTRAN Genetic Algorithm (GA) Driver (Carrol 1999 ) is used for the numerical results; a population of 20 individuals and a number of 1,000 generations are chosen. The adoption of a genetic optimization algorithm is suggested on one hand by the presence of integer variables (e.g., the number of fan blades) - which are difficult to handle using a gradient-based method - and on the other hand by the noisy nature of the objective. The centre of the variables domain is taken as a reference configuration for later comparison.

\subsection{Set of variables no. 1}

Figures 4 and 5 compare the third-octave band spectra relative to the reference configuration, with the spectra of the target sounds 1 and 2, respectively. Each picture presents the three time slots considered, corresponding to 14 secsonds before flyover (slot a), the flyover (slot b), and 14 seconds after flyover (slot c). The grey area gives a visual estimate of the $L^{1}$-difference between the two sounds. As mentioned, the objective function used is obtained from Eq. 9, with $w_{k}=0, \forall k$, and $w_{\Delta}=1$. The latter is defined here as the $L^{2}$-norm $(p=2)$ of the difference between the current and the target spectra, suitably normalized so to have the same $L^{1}$-norm (since the focus is on the spectrograms shape).

Figures 6 and 7 depict the final spectra. The results reveal that the method is able to effectively drive the optimization procedure towards the desired matching to the target. In both cases, the final spectra are remarkably closer to the targets along the whole frequency range. Moreover, the objective is plotted as a function of the flaps deflection angle in Figure 8, and as a function of the engines' primary shaft rotational speed in 


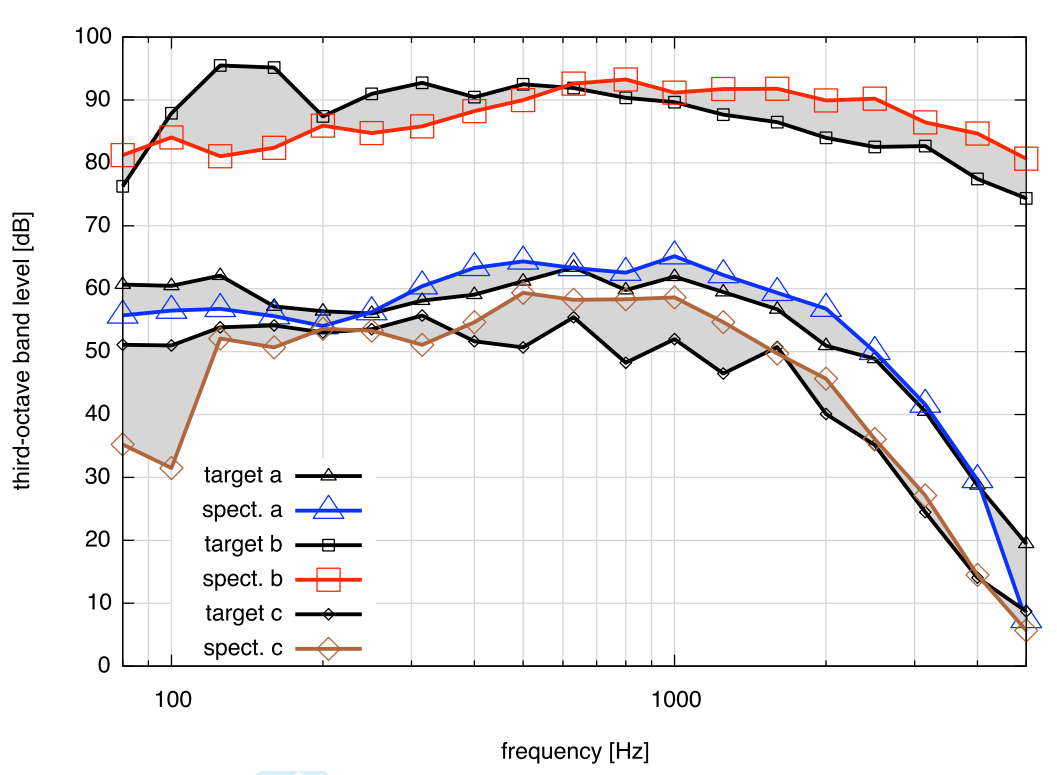

Figure 4. Target sound no. 1: Comparison between reference and target spectrum (a) 14 sec. prior flyover, (b) at flyover and (c) 14 sec. after flyover.

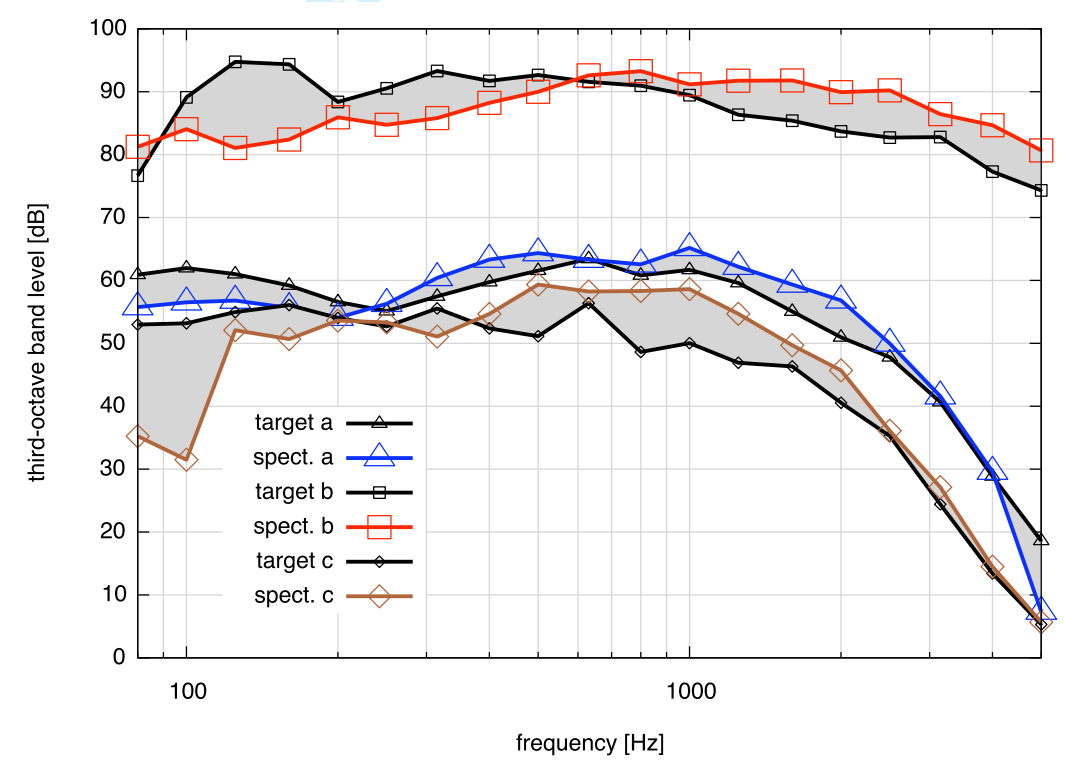

Figure 5. Target sound no. 2: Comparison between reference and target spectrum (a) 14 sec. prior flyover, (b) at flyover and (c) 14 sec. after flyover.

Figure 9, respectively.

It is worth noting the remarkable difference between the overall shape of the objective function with respect to the two variables: smooth an slowly varying in the first case, and peaky, with discontinuous derivative in the second. The reason for this difference can be explained by considering the role that the chosen variables have in the noise generation mechanism. The flap deflection angle affects primarily the airframe noise, which has a broadband contribution. As a consequence, small variations of this variable yield small, distributed variations on the overall shape of the spectrum, resulting in a small and continuous variation of the objective function. Conversely, the rotational speed 


\section{Мay 10, 2011 \\ Engineering Optimization}

Engineering Optimization

of the engine's primary shaft affects the tonal components related to the blade passing frequencies of the rotating machineries (fan and compressor noise, buzz-saw noise, etc.). Variations of the primary shaft RPM result in the displacement (in the frequency domain) of the tones produced by the engine. Thus, small variations of the engine primary shaft RPM, yield significant and discontinuous variations of the difference from the target, causing the peaky behavior of the objective function as in Figure 9.

The markers depicted in Figures 8 and 9 indicate the final solution of the optimization procedure.

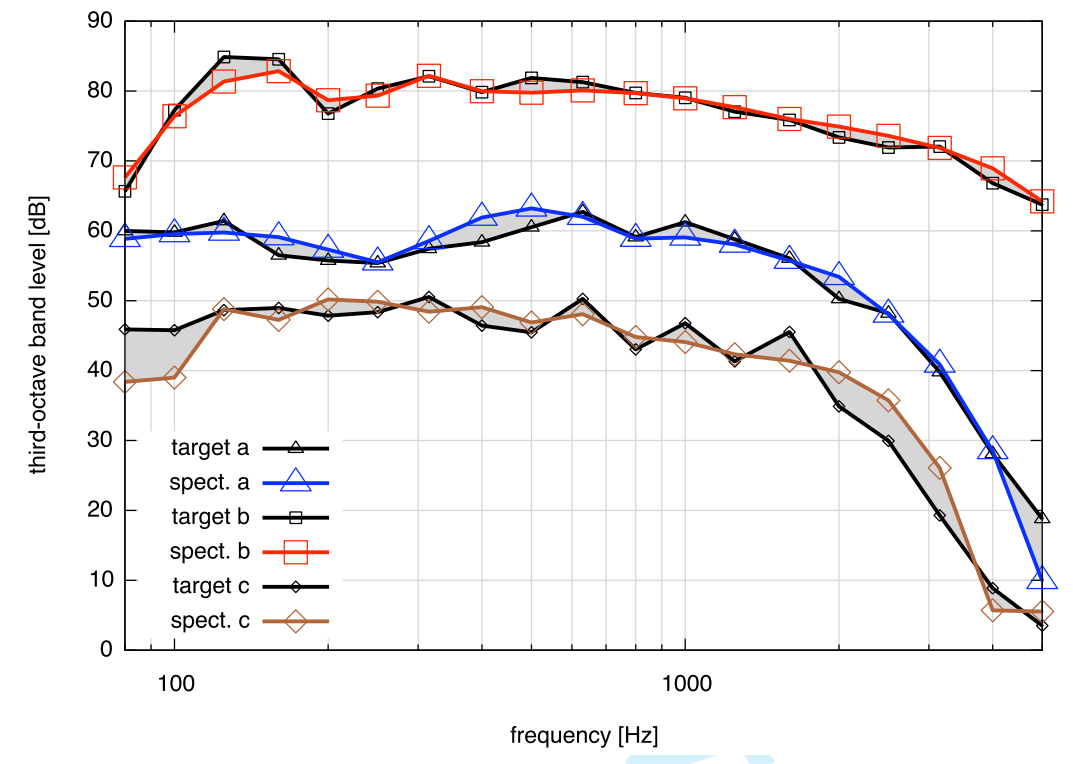

Figure 6. Variables set no. 1, target sound no. 1: comparison between final and target spectrum (a) 14 sec. prior flyover, (b) at flyover and (c) 14 sec. after flyover.

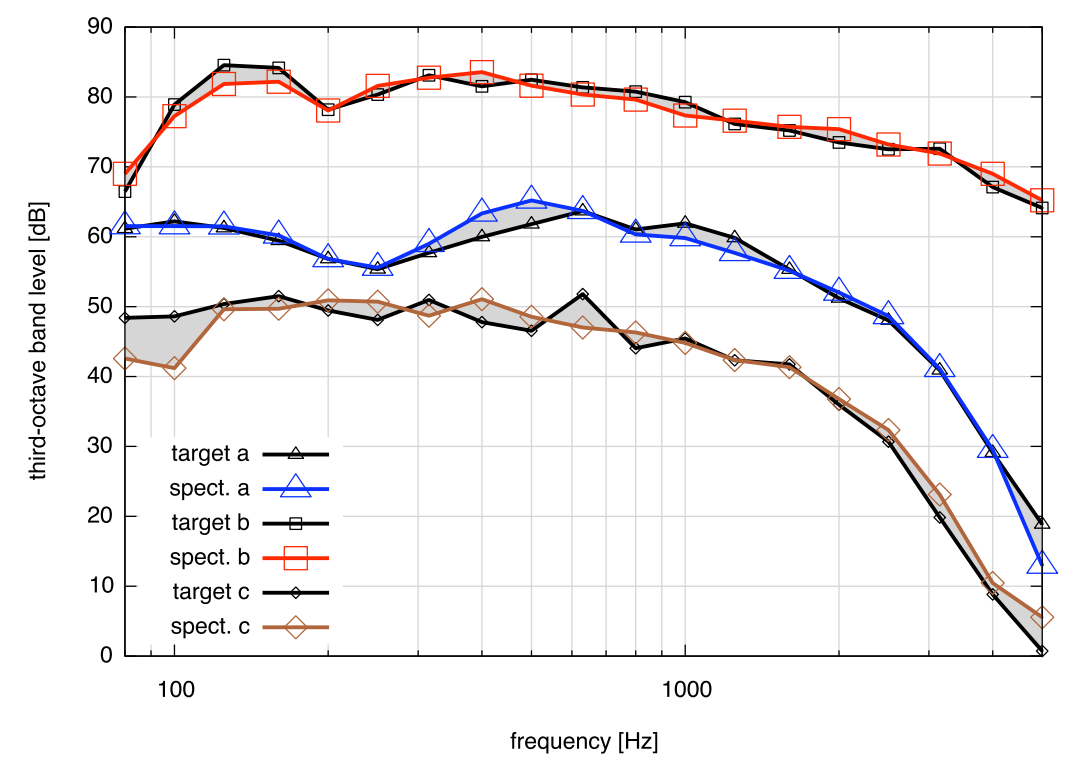

Figure 7. Variables set no. 1, target sound no. 2: comparison between final and target spectrum (a) 14 sec. prior flyover, (b) at flyover and (c) 14 sec. after flyover. 
In Figure 10, the optimal sets obtained using the two target sounds are normalized with respect to their reference values, and compared (see also Table 5). In both cases, the algorithm increases the broadband noise in the lower part of the spectrum to achieve a good matching to the target. This is done by increasing the relative size of the high-lift devices, thus increasing the overall airframe noise. The presence of the two pronounced high tones in target no. 1 produces an increase of the engine primary shaft rotational speed and of the number of fan blades (resulting in an increase of the blade passing frequency). Finally, an additional effect can be noticed. The variables related to the engine exhaust (mass flow rate, main nozzle diameter, main jet speed, jets area, and jets 


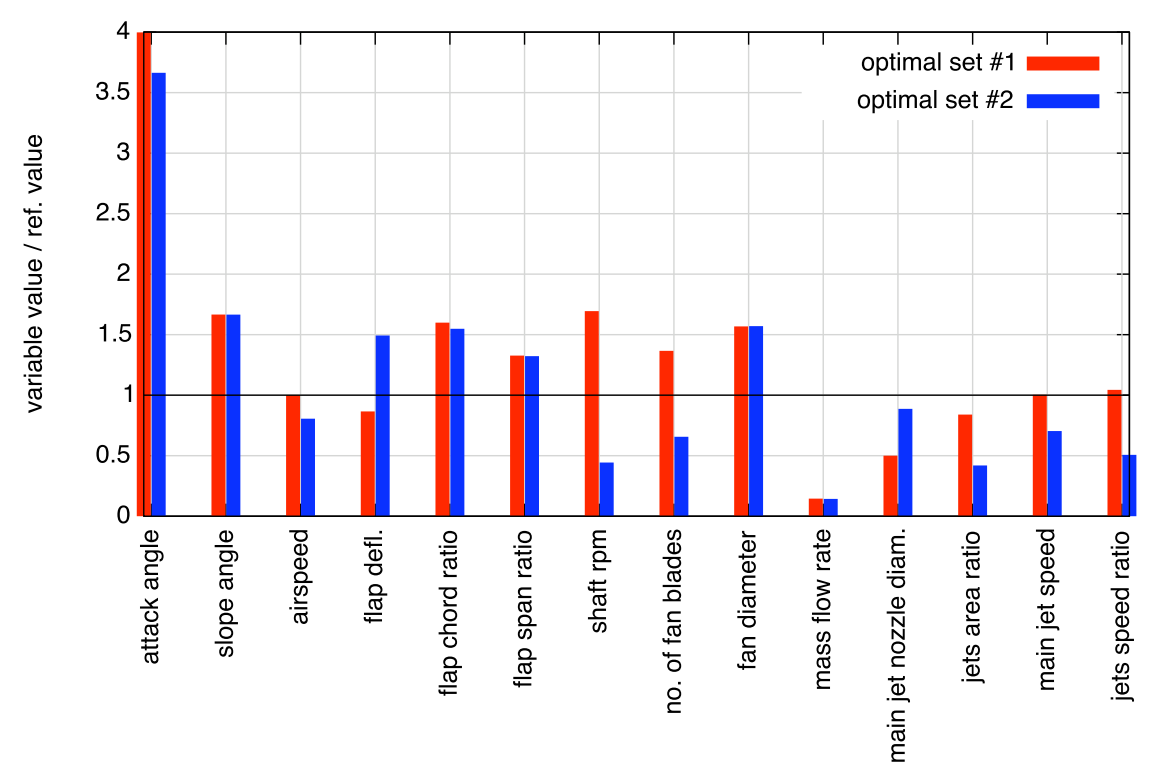

speed ratios) are modified by the optimization algorithm, so as to increase the level of the jet noise. This is likely due to the fact that the higher tones present in the target spectrum are located in the frequency range where the jet emissions have the maximum energy content. Being the sounds comparison performed on the basis of a third-octaveband representation of the spectra, the optimization algorithm attempts the matching by increasing all the contributions (tonal and broadband) lying in that frequency range.

Figure 10. Comparison between vector solutions obtained using targets no. 1 and no. 2, for the first set of variables.

The considerations made for the target no. 1 are confirmed by the results obtained for target no. 2, which differs in the reduction by $8 \mathrm{~dB}$ of the two highest tones. The optimization algorithm tries to cope with the lack of the pronounced tones in the higher part of the spectrum in two different ways: $i$ ) the number of fan blades is reduced, in order to move the blade passing frequency towards the lower part of the spectrum, and mask the relative tones with the lower part of the broadband noise; $i i)$ the engine is idle. Jet related variables behave in the opposite way, with respect to the previous test, thus confirming the hypothesis made.

\subsection{Set of variables no. 2}

The variables space used for the second set of numerical experiments is enriched by the parameters shown in Table 4. Specifically, the variables included in the optimization process are those defining the planform of the wing and its built-in angles of attack at root and tip. The final matching to the targets is very good for both targets, as can be seen by the value of the objective function achieved with the second variables set (see Figures 11 to 13). Is is worth stressing that, as already stated, the optimization procedure takes into account only the sounds matching criterion, disregarding aircraft performances. Therefore, the results have to be interpret exclusively from the sound quality point of view. 


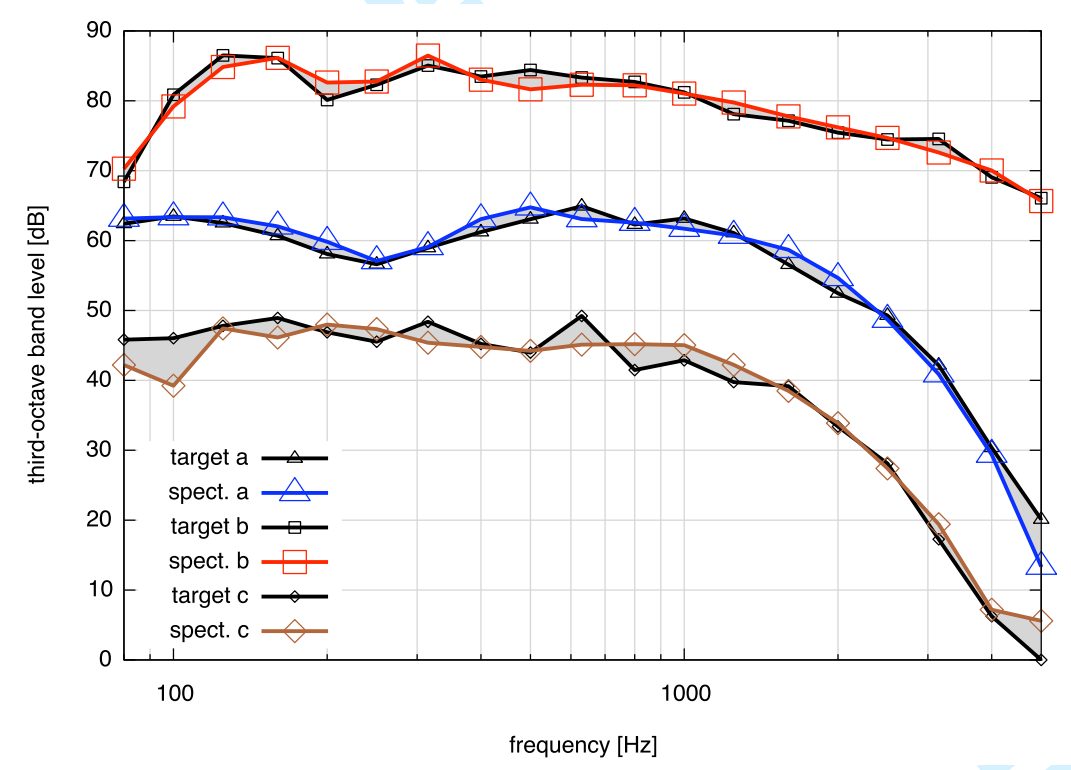

Figure 12. Variables set no. 2, target sound no. 2: comparison between final and target spectrum (a) 14 sec. prior flyover, (b) at flyover and (c) 14 sec. after flyover.

The examination of the final configurations obtained (Figure 13 and Table 6) reveals that most of the considerations made in Section 6.1 are still valid. In addtion, in this preliminary design exercise, the optimizer seems to choose a radical modification of the aerodynamics (wing geometry, flap settings and aircraft attitude) in order to modify the level of the broadband noise. 
Figure 13. Comparison between vector solutions obtained using targets no. 1 and no. 2, for the second set of variables.

\section{Concluding remarks}

An novel approach for the inclusion of sound-quality-based community noise considerations in the MCDO of commercial aircraft has been presented and discussed. The methodology provides the designer with an additional degree of freedom for the alleviation of the community noise due to the aircraft operations. The approach relies on an unconventional objective function, based on the measure of the difference between the noise emitted by the aircraft under analysis and a given target sound. This is defined as a "weakly annoying" noise and used here as an input. The measure of the difference between sounds is obtained by evaluating the $L^{p}$-norm of the time-varying spectral difference. In other words, the objective function is defined as the $L^{p}$-norm of the difference between the current and the target spectrograms. Preliminary numerical results, performed in order to assess the whole methodology, show that the sound-matching-based objective function is effectively capable to drive the optimization process towards the desired matching to the target. It is worth noting that this unconventional approach to the conceptual design introduces a number of additional difficulties, related to the need of accurate and reliable models for the prediction of the acoustic emission of the aircraft in the frequency domain (typically not necessary in a classical conceptual design framework).

The extension of this work to a complete and exhaustive MCDO procedure aimed at the identification of novel aircraft configurations, requires an adequate modeling of the join between the propulsion system parameters and the noise prediction models. This is not completely available at the present stage of the work and will be addressed in the future. 


\section{Acknowledgements}

This work has been partially supported by the European Commission through the research project "Sound Engineering For Aircraft" (SEFA), VI Framework Programme 2004-2007, Contract No. AST3-CT-2003-502865. The authors greatly acknowledge Dr. Vincenzo Marchese for his support in the implementation of the algorithm.

\section{References}

Abbott, H. I., Von Doenhoff, E. A., 1959. Theory of wing sections. Dover Publications, New York, Ny.

Alexandrov, N. M., 1996. Robustness properties of a trust region framework for managing aproximation in engineering optimization. AIAA Paper 96-4112, in proceedings of 6th AIAA/NASA/USAF Multidisciplinary Analysis \& Optimization Symposium, Bellevue, WA, US.

Alexandrov, N. M., Lewis, M., 2001. An overview of first-order model for engineering optimization. Optimization and Engineering, Vol. 2, pp. 413-430.

Antoine, N. E., Kroo, I. M., 2004. Aircraft optimization for minimal environmental impact. AIAA Journal of Aircraft, Vol.41 No.4, pp. 790-797.

Antoine, N. E., Willcox, K., and Barter, G., 2004. A framework for aircraft conceptual design and environmental performance studies. AIAA Paper 2004-4314, in proceedings of 10th AIAA/ISSMO Multidisciplinary Analysis and Optimization Conference, Albany, NY, US.

Attenborough, K., 1992. Ground parameter information for propagation modeling. Journal of the Acoustical Society of America, Vol. 92, No. 1, pp. 418-427.

Babuska, I., and Strouboulis, T., 2001. The finite element method and its reliability. Oxford University Press, UK.

Soemarwoto, B.I., 1998. Inverse aerodynamic shape design using the Navier-Stokes Equations. In: Inverse Problems in Engineering Mechanocs, Tanaka and Dulikravich Eds., Elsevier Science B.V.

Barbot, B., Lavandier, C., and Cheminèe, P., 2008. Perceptual representation of aircraft sounds. Applied Acoustics, Vol. 69, No. 11, pp. 1003-1016.

Bisping R., 2005. Aircraft target sound design. In proceedings of 12th International Congress on Sound and Vibration, ICSV12, Lisbon, Portugal.

Bisping R., Dickson C., Shafiquzzaman Khan, 2006. Psychometric analysis of stationary aircraft sounds. In proceedings of 13th International Congress on Sound and Vibration, ICSV13, Vienna, Austria.

Brentner, K. S., Farassat, F., 1998. Analytical comparison of the acoustic analogy and Kirchhoff formulation for moving surfaces. AIAA Journal, Vol. 36, No. 8, pp. 13791386 .

Carroll, D.L., 1999. FORTRAN Genetic Algorithm (GA) Driver. Available from: http://www.cuaerospace.com/carroll/ga.html.

Caves, B.E., Jenkinson, L.R., and Rhodes, D.P., 1997. Adapting Civil Aircraft Conceptual Design Methods to Account for Broader Based Constraints. AIAA Paper 97-5595, World Aviation Congress, Anaheim, CA, US.

Caves, B.E., Jenkinson, L.R., and Rhodes, D.P, 1998. Development of an Integrated Conceptual Aircraft Design and Aircraft Noise Model for Civil Transport Aircraft. ICAS Paper 98-6,4,3, 21st ICAS Congress, Melbourne, Australia. 
Diez M., Iemma U., Marchese V., 2007. A sound-matching-based approach for aircraft noise annoyance alleviation via MDO. AIAA Paper 2007-3667, in proceedings of 13th AIAA/CEAS Aeroacoustics Conference, Rome, Italy.

Diez M., Iemma U., 2007. Robust optimization of aircraft life-cycle costs including the cost of community noise. AIAA Paper 2007-3668, in proceedings of 13th AIAA/CEAS Aeroacoustics Conference, Rome, Italy.

Fink, M. R., 1977. Airframe noise prediction. FAA-RD 77-29.

Goldberg, D. E., 1989. Genetic algorithms in search, optimization, and machine learning. Addison-Wesley Pub. Co.

Hawkings, D., 1971. Multiple tone generation by transonic compressors. J. Sound Vib., Vol. 17, No. 2, pp. 241-250.

Heidmann, M. F., 1975. Interim prediction for fan and compressor source noise. NASA TMX 71763.

Hill, G.A. and Olson, E.D, 2004. Applications of Response Surface-Based Methods to Noise Analysis in the Conceptual Design of Revolutionary Aircraft", AIAA Paper 20044437, 10th AIAA/ISSMO Symposium on Multidisciplinary Analysis and Optimization, Albany, NY, US.

Hosder, S., Schetz, J.A., Grossman, B., and Mason, W.H., 2004. Airframe Noise Modeling Appropriate for Multidisciplinary Design and Optimization. AIAA Paper 2004-0698, AIAA Aerospace Sciences Meeting and Exhibit, Reno, NV, US.

Iemma, U., Diez, M., 2006. Optimal conceptual design of aircraft including community noise prediction. AIAA Paper 2006-2621, in proceedings of 12th AIAA/CEAS Aeroacoustics Conference, Cambridge, MA, US.

Iemma, U., Diez, M., Marchese, V., 2006a. Matching the aircraft noise to a target sound: a novel approach for optimal design under community noise constraints. In proceedings of 13th International Congress on Sound and Vibration, ICSV13, Vienna, Austria.

Iemma, U., Diez, M., Marchese, V., 2006b. Sculpting the sound of aircraft: a novel MDO approach for noise annoyance alleviation. In proceedings of 2nd International Conference on Air Transportation, ICRAT 2006, Belgrade, Serbia.

Iemma, U., Diez, M., Morino, L., 2005. Community noise impact on the conceptual design of innovative aircraft configurations. AIAA Paper 2005-2982, in proceedings of 11th AIAA/CEAS Aeroacoustics Conference, Monterey, CA, US.

Iemma, U., Gennaretti, M., 2005. Reduced-order modeling for linearized transonic fixedwing aeroelasticity. Journal of Fluids and Structures, Vol. 21, No. 3, pp. 243-255.

Ilyin, A.V., Chaika, T.Y., Mirzoyan, A.A., Egorov. I.N., Kretinin, G.V., 2004. Ro- bust optimization of integrated aircraft-propulsion system control to meet takeoff noise requirements of supersonic business jet. International Journal of Aeroacoustics, Vol. 3, No. 3, pp. 271-287.

Janssens, K., Vecchio, A., Van der Auweraer, H., 2005. Model-based synthesis approach for vehicle and aicraft noise. In proceedings of Euronoise Conference, Tampere, Finland.

Leifsson, L., Mason, W., Schetz, J., Grossman, B., and Haftka, R., 2006. Multidisciplinary Design Optimization of Low-Airframe-Noise Transport Aircraft. AIAA-20060230. 44th AIAA Aerospace Sciences Meeting and Exhibition, Reno, NV, US.

Lighthill, M.J., 1958. On displacement thickness. Journal Fluid Mech., Vol. 4, pp. 383392.

Manneville, A., Pilczer, D., and Spakovszky, Z.S. Noise Reduction Assessments and Preliminary Design Implications for a Functionally-Silent Aircraft", 10th AIAA/CEAS Aeroacoustics Conference. AIAA Paper 2004-2925. 
Mastroddi, F., Bonelli, C., Morino, L., Bernardini, G., 2002. Multidisciplinary design and optimization for fluid-structure interactions. In proceedings of 5th ASME FluidStructure Interaction, Aeroelasticity, Flow-Induced Vibration \& Noise Symposium , New Orleans, LA, US.

Mastroddi, F., Ciancaleoni, E., Morino, L., 1999. Aeroelastic constraints in MDO. In proceedings of CEAS/AIAA/ICASE/NASA Langley International Forum on Aeroelasticity and Structural Dynamics, Williamsburg, VA, US. NASA/CP-1999-209136/PT1, pp. 33-42.

Mastroddi, F., Morino, L., Bernardini, G., Simonetti, R., 2001. MDO for preliminary design of a highly innovative configuration. In proceedings of CEAS International Forum on Aeroelasticity and Structural Dynamics, Madrid.

Morfey, C.L., Fisher, M.J., 1970. Shock-wave radiation from a supersonic ducted rotor. Aeronaut. J., Vol. 74, No. 715, pp. 579-585.

Morino, L., 1993. Boundary integral equations in aerodynamics. Appl. Mech. Rev., Vol. 46, 1993, pp. 445-466.

Morino, L., Bernardini, G., 2001. Singularities in BIE's for the Laplace equation; Joukowski trailing-edge conjecture revisited. Journal of Engineering Analysis with Boundary Elements, Vol. 25, pp. 805-818.

Morino, L., Bernardini, G., Da Riz, W., Del Rio, V., 2002. Aerodynamic issues in MDO for preliminary design of an innovative configuration. In proceedings of IABEM 2002 (International Association for Boundary Element Methods), Austin, TX, US.

Morino, L., Bernardini, G., De Gregorio, D., Willcox, K. E., Harris, W. L., 2004. Life-cycle cost multidisciplinary optimization for Prandtl-plane. In proceedings of International Conference on Computational \& Experimental Engineering \& Sciences (ICCES'04), Madeira, Portugal.

Morino, L., Bernardini, G., and Mastroddi, F., 2003. First-principle based dynamic aircraft modeling for MDO. Keynote lecture at the International Conference on Computational and Experimental Engineering and Sciences (ICCES'03), Corfu, Greece.2003.

Morino, L., Iemma, U., Bernardini, G., Diez, M., 2004. Community noise considerations in multidisciplinary optimization for preliminary design of innovative configurations. AIAA Paper 2004-2809, in proceedings of 10th AIAA/CEAS Aeroacoustics Conference, Manchester, UK.

Morino, M., Mastroddi, F., De Troia, R., Ghiringhelli, G. L., Mantegazza, P., 1995. Matrix fraction approach for finite-state aerodynamic modeling. AIAA Journal, Vol. 33. No. 4, pp. 703-711.

Morino, L., Salvatore, F., Gennaretti, M., 1997. A velocity decomposition for viscous flows: Lighthill equivalent-source method revisited. In: Morino, L., and Wendland, W.L., (eds.): Boundary integral methods for nonlinear problems, pp. 161-166. Kluwer Academic Publishers, Dordrecht, The Netherlands.

Mueller, U., Schutte, M., 2006. Sound Engineering for Aircraft (SEFA), first results of listening examinations. In proceedings of Internoise 2006, Honolulu, HI, US.

Olsen, W., Friedman, R., 1974. Jet noise from coaxial nozzles over a wide range of geometric and flow parameters. AIAA Paper 74-43, In proceedings of 12 th AIAA Aerospace Science Meeting, Washington DC, US.

Philpot, M.G., 1971. The buzz-saw noise generated by a high duty transonic compressor. J. Engng Pwr, pp. 63-69.

Royden, H., L., 1969. Real Analysis - second edition. The MacMillan Company, New York.

Ruijgrok, G.J.J., 2000. Elements of aviation acoustics. Het Spinhuis Pub., Amsterdams, 


\section{Appendix A. Multidisciplinary analysis models for conceptual aircraft design}

The aim of this appendix is to provide the reader with an overview of the models and algorithms used for the aircraft conceptual design multidisciplinary analysis. Specifically, this appendix deals with the analysis modules developed by the authors and their collaborators during the last 15 years, and carefully validated throughout this period. A detailed review of this validation process is beyond the scope of the present paper. The interested reader is addressed to the extensive bibliography produced. In particular, the works by Mastroddi et al. (1999, 2001, 2002), Morino (1993), Morino and Bernardini (2001), Morino et al. (1995, 1997, 2002, 2003, 2004), and Iemma and Gennaretti (2005) are of relevance in the present context.

The analysis modules implemented in the MCDO in order to describe the complete mechanics of the aircraft, cover statics and dynamics of the structures, steady and unsteady aerodynamics, aeroelasticity, flight mechanics, performances and life-cycle-cost estimate. The models used are, whenever possible, first-principle based, so that they may be used for the analysis of highly innovative configurations, for which the designer cannot rely upon past experience.

For the sake of conciseness, the theoretical models underlying the algorithms used are only briefly outlined, and the description of the life-cycle-cost estimator is omitted, because not relevant in the present context. In order to emphasize their mutual interaction, flight mechanics and aeroacoustics have been presented in Section 4.

\section{A.1. Structural analysis}

The wing structure is modeled as a three-dimensional bending-torsional beam, with geometric and structural parameters varying in the spanwise direction. The variables taken into account include the geometric dimensions of the structural elements (rib area, spar and skin panel thickness, etc.), the wing twist, the mass distribution, and bending and torsional moments of inertia. Clamped boundary conditions are considered at the root in order to take into account the wing-fuselage juncture. The solution of the structural problem is obtained using the modal approach. The approximate modes of vibration, $\boldsymbol{\Phi}_{m}(\mathbf{x})$, are evaluated by a finite-element model of the wing, and used to express the displacement field as $\mathbf{u}(\mathbf{x}, t)=\sum_{m=1}^{M} q_{m}(t) \boldsymbol{\Phi}_{m}(\mathbf{x})$. The resulting Lagrange equations of motion are $\ddot{\mathrm{q}}+\Omega^{2} \mathrm{q}=\mathrm{e}$, where $\mathrm{q}$ denotes the Lagrangian-coordinate vector, $\Omega$ the diagonal matrix of the wing natural frequencies, and $\mathrm{e}=\left\{e_{n}\right\}$ the vector of the generalized forces. 


\section{A.2. Aerodynamics}

The aerodynamics is based upon a compressible, quasi-potential flow model with a boundary layer correction as appropriate for civil aviation aircraft where the flow is typically attached. A quasi-potential flow is a flow which is potential almost everywhere, i.e., such that the vorticity remains concentrated within a domain of zero measure. For the flow around a lifting body, this domain is represented by the wake surface, that is the locus of the material points that came in contact with the trailing edge of the wing (see, e.g., Morino et al. 2003). The potential model is enriched by a boundary-layer integral model, to take into account the effects of viscosity, and provide an adequate estimate of the viscous drag. Under the assumption that the wake geometry remains fixed in a frame of reference connected with the wing, the numerical solution is obtained through a BEM, to yield $\tilde{\mathrm{f}}_{\varphi}=\mathrm{E}_{I E}(s) \tilde{\mathrm{f}}_{\chi}$. The vectors $\tilde{\mathrm{f}}_{\varphi}=\left\{\tilde{\varphi}_{j}\right\}$, and $\tilde{\mathrm{f}}_{\chi}=\left\{\tilde{\chi}_{j}\right\}$ comprise the values of the velocity potential, $\tilde{\varphi}$, and its normal derivative, $\tilde{\chi}$, at the centres of the surface elements, and $s$ is the Laplace variable (see Morino et al. 2003 for details). Note that the $\tilde{\chi}$ includes the effect of the boundary-layer in form of a transpiration velocity. The latter is evaluated following the method presented in Lighthill (1958).

The effect of the high-lift devices is taken into account through a correction of the lift coefficient. Specifically, the lift coefficient per unit span, $C_{l}$, is evaluated for the clean configuration using the boundary integral formulation introduced above, and the contribution of the high-lift devices, $C_{l f}$, is given by (only plain flaps are considered in this work, see e.g., Abbott and Von Doenhoff 1959)

$$
C_{l f}:=\frac{l_{f}}{q_{D} c_{f}}=y_{1}\left(\frac{c_{f}}{c_{w}}\right) C_{l}+y_{2}\left(\frac{c_{f}}{c_{w}}\right) \delta
$$

Here, $l_{f}$ is the section flap lift, $q_{D}$ is the dynamic pressure, $\delta$ is the flap deflection angle and $y_{1}$ and $y_{2}$ are known functions of the ratio between flap chord $c_{f}$ and wing chord $c_{w}$.

\section{A.3. Aeroelasticity}

The aeroelastic feedback generated by the interaction between unsteady aerodynamics and structural dynamics is also taken into account in the MCDO formulation. Under the assumption of linear unsteady aerodynamics ${ }^{1}$, the relationship between the structural Lagrangean variables $\tilde{\mathrm{q}}$, and generalized forces ẽ can be written as $\tilde{\mathrm{e}}=q_{D} \mathrm{E}(\hat{s}) \tilde{\mathrm{q}}$, where $\hat{s}=s \ell / U_{\infty}$ is the complex reduced frequency (i.e., the dimensionless Laplace variable), $q_{D}$ is the dynamic pressure, and the aerodynamic matrix $\mathrm{E}(\hat{s})$ depends transcendentally on $\hat{s}$, due to the presence of the convection and compressibility delays. In order to perform efficiently the aeroelastic analysis within the optimization procedure, a reduced order model (ROM) for $\mathrm{E}(\hat{s})$ is introduced. By doing so, the aeroelastic stability analysis is reduced to the study of a root locus (see Morino et al. 1995 for details).

\footnotetext{
${ }^{1}$ The formulation is currently being extended to the analysis of transonic flows, through linearization of an original full-potential boundary integral formulation (see Iemma and Gennaretti 2005).
} 


\section{A.4. Propulsion}

Community noise considerations based on sound quality require the modeling of the propulsion system with a level of detail not needed in standard MCDO. Indeed, most of the relevant noise sources (tonal and broadband) depend on the operating conditions of the engines. As a consequence, the level of detail needed in the modeling of the engines is higher than that usually needed in the conceptual design optimization aimed at aircraft performances, where the propulsion system typically appears as a simple "fuel-burningthrust-provider". The block diagram in Figure A1 gives a schematic picture of the links required to estimate the noise emissions: $i$ ) the flight mechanics module receives as an input (from the designer, or as the output of the other modules) the flight Mach number $M$, and the lift, drag, and moment coefficients; $i i)$ the flight mechanics module provides, in output, the trajectory of the centre of mass, the attitude, and the thrust required; iii) the engine simulation module evaluates the operating conditions compatible to the required thrust at the given flight speed, in terms of primary shaft rotational speed, temperature rise in the combustion chamber, and the enthalpy jump across the nozzle (some iteration is typically required to achieve convergence). The engine operating point thereby evaluated, is used as an input for the noise prediction modules, in order to estimate the propulsion components of the spectrum. It is worth noting that, during the optimization procedure, each module can be called thousands of times, and, therefore, an appropriate trade-off between accuracy and computational efficiency is crucial.

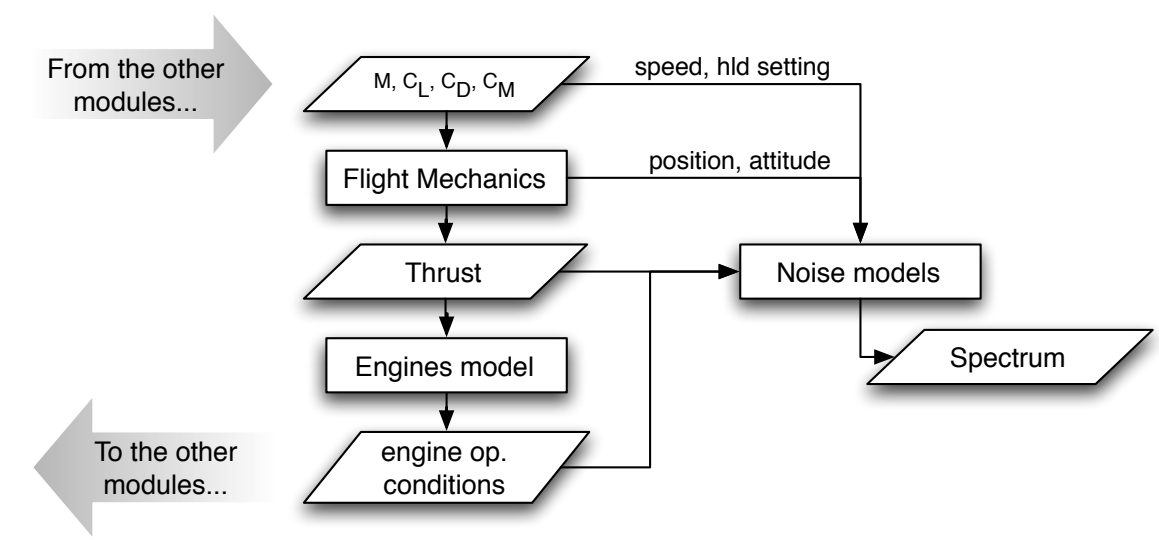

Figure A1. Link between flight mechanics, propulsion, and noise predictors ( $M=$ flight Mach no., $C_{L}=$ lift coef., $C_{D}=$ drag coef., $C_{M}=$ moment coef.).

In the present work, we adopt a simple, semi-empirical model developed by the authors. Specifically, a Thrust-Mach no.-RPM relationship is obtained, for a specific engine model, by interpolating data available to the authors. This semi-empirical function appears adequate to guarantee a relation between the flight mechanics and the engine operating conditions. It is worth noting that this level of detail is not sufficient to have a reliable estimate of the combustion and jet noise components. Nevertheless, this limitation is not critical in the present preliminary application, focused on the effectiveness of the objective function used to improve the aircraft sound quality. Nonetheless, a more accurate modeling of the thermo-fluiddynamics of the engine is a worthwhile enhancement in the further development of the method, perhaps exploiting the benefits of the most recent algorithms for the management of multi-fidelity schemes (see, e.g., for instance, Alexandrov and Lewis 2001 and Alexandrov 1996). 


\section{A.5. Performances}

In order to evaluate the fuel consumption, the mission profile considered in this work consists of: (i) take-off, $(i i)$ climb, $(i i i)$ cruise, $(i v)$ descent, and $(v)$ landing. The range is computed according to Breguet equation $R=\left(V_{c} E / c\right) \ln \left(W_{i} / W_{f}\right)$, where $V_{c}$ is the cruise speed, $c$ is the specific fuel consumption, $E=L / D$ is the aerodynamic efficiency (lift to drag ratio), and $W_{i}$ and $W_{f}$ the initial and final weights of the cruise segment, respectively. Finally, expressing the fuel consumptions for the mission segments before and during the cruise as fractions of the usable fuel weight $F$ (indicated as $k_{1}$ and $k_{2}$, respectively), $W_{i}$ and $W_{f}$ can be written as $W_{i}=W-k_{1} F$ and $W_{f}=W-\left(k_{1}+k_{2}\right) F$, and $F$ can be easily evaluated.

\section{Appendix B. Penalty function}

In this work, the constrained minimization problem is handled using a penalty function method. It may be noted that the equality constraints that appear in the problem of Eq. 10 are explicitly satisfied within the multidisciplinary analysis by trimming the aircraft.

Considering the inequality constraints of the minimization problem of Eq. 10, the following penalty parameters are defined:

$$
p_{n}(\mathbf{x})= \begin{cases}g_{n}(\mathbf{x}), & \text { if } g_{n}(\mathbf{x})>0 \\ 0, & \text { otherwise }\end{cases}
$$

thus defining the total penalty function of the $q$-th order

$$
p_{\text {tot }}(\mathbf{x})=\frac{1}{\varepsilon} \sum_{n=1}^{N} p_{n}^{q}(\mathbf{x})
$$

where $\varepsilon \in \mathbb{R}^{+}$and $q \in \mathbb{N}$. In this work, $\varepsilon=10^{-3}$ and $q=1$, hence defining a linear penalty function.

Finally, the minimization problem is solved taking into account the merit factor (or pseudo-objective) $O \hat{B} J(\mathbf{x}):=O B J(\mathbf{x})+p_{t o t}(\mathbf{x})$, see problem of Eq. 10. 


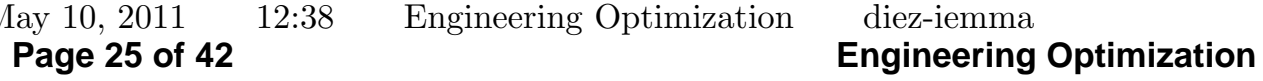

Engineering Optimization

\section{Tables}

Table 1. Variables set no. 1, including lower and upper bounds.

\begin{tabular}{lcccc}
\hline Design/procedural variables & & lower b. & upper b. & classification \\
\hline fuselage angle of attack, deg & $\alpha$ & -6.00 & 12.00 & \\
slope angle, deg & $\gamma$ & 1.00 & 5.00 & \\
airspeed, m/s & $U_{\infty}$ & 60.00 & 160.00 & procedure \\
flap deflection angle, deg & $\delta$ & 0.00 & 60.00 & (landing) \\
shaft rpm & $n_{s}$ & 1,000 & 9,000 & \\
\hline flap span (as a ratio of wing span) & $l_{f} / l_{w}$ & 0.40 & 0.80 & high-lift devices \\
flap chord (as a ratio of wing chord) & $c_{f} / c_{w}$ & 0.10 & 0.30 & design \\
\hline number of fan blades & $n_{b}$ & 18 & 42 & \\
fan diameter, m & $d_{f}$ & 0.6 & 2.2 & \\
mass flow rate (engine), kg/s & $m$ & 100.00 & 1300.00 & \\
jet nozzle diameter (primary), m & $d_{1}$ & 0.20 & 0.60 & engine \\
jets area ratio & $A_{2} / A_{1}$ & 1.00 & 11.00 & \\
jet speed (primary), m/s & $u_{1}$ & 200.00 & 400.00 & \\
jets speed ratio & $u_{2} / u_{1}$ & 0.20 & 0.60 & \\
& & & & \\
\hline
\end{tabular}

Table 2. Additional variables for set no. 2, including lower and upper bounds.

\begin{tabular}{lcccc}
\hline Desing/procedural variables & & lower b. & upper b. & classification \\
\hline span, $\mathrm{m}$ & $l_{w}$ & 24.00 & 40.00 & \\
root chord, m & $c_{w, r}$ & 2.00 & 10.00 & \\
tip chord, m & $c_{w, t}$ & 0.50 & 2.50 & wing design \\
root built-in angle of attack, deg & $\alpha_{0, r}$ & 0.00 & 12.00 & \\
tip built-in angle of attack, deg & $\alpha_{0, t}$ & 0.00 & 8.00 & \\
sweep angle, deg & $\delta_{w}$ & 10.00 & 50.00 & \\
\hline
\end{tabular}

Table 3. Design requirements.

\begin{tabular}{lc}
\hline number of seats & 150 \\
payload, kg & 16,600 \\
weight empty, kg & 42,000 \\
landing weight, kg & 64,000 \\
number of engines & 2 \\
max thrust per engine, lb & 25,000 \\
engine placement & under the wing \\
\hline
\end{tabular}

URL: http:/mc.manuscriptcentral.com/geno Email: A.B.Templeman@liverpool.ac.uk 
M. Diez and U. Iemma

Table 4. Wing baseline configuration.

\begin{tabular}{lcc}
\hline & $l_{w}$ & 32.00 \\
span, m & $c_{w, r}$ & 6.00 \\
root chord, m & $c_{w, t}$ & 1.50 \\
tip chord, m & $\alpha_{0, r}$ & 6.00 \\
root built-in angle of attack, deg & 4.00 \\
tip built-in angle of attack, deg & $\alpha_{0, t}$ & 4.00 \\
sweep angle, deg & $\delta_{w}$ & 25.00 \\
\hline
\end{tabular}

Table 5. Optimized parameters for sound matching using variables set no. 1.

\begin{tabular}{lccc}
\hline Desing/procedural variables & & target no.1 & target no.2 \\
\hline fuselage angle of attack, deg & $\alpha$ & 11.99 & 10.99 \\
slope angle, deg & $\gamma$ & 5.00 & 5.00 \\
airspeed, m/s & $U_{\infty}$ & 110.24 & 88.65 \\
flap deflection angle, deg & $\delta$ & 17.32 & 29.86 \\
flap span (as a ratio of wing span) & $l_{f} / l_{w}$ & 0.80 & 0.79 \\
flap chord (as a ratio of wing chord) & $c_{f} / c_{w}$ & 0.40 & 0.39 \\
shaft rpm & $n_{s}$ & 8,473 & 2,218 \\
number of fan blades & $n_{b}$ & 41 & 19 \\
fan diameter, m & $d_{f}$ & 2.19 & 2.20 \\
mass flow rate (engine), kg/s & $m_{1}$ & 101.86 & 100.07 \\
jet nozzle diameter (primary), m & $d_{1}$ & 0.20 & 0.35 \\
jets area ratio & $A_{2} / A_{1}$ & 5.04 & 2.51 \\
jet speed (primary), m/s & $u_{1}$ & 300.66 & 211.13 \\
jets speed ratio & $u 2 / u_{1}$ & 0.41 & 0.20 \\
\hline objective, dB & $\Delta_{p}$ & 2.64 & 2.20 \\
\hline
\end{tabular}




\section{$\begin{array}{lll}\text { May 10, 2011 } 12: 38 & \text { Engineering Optimization } & \begin{array}{r}\text { diez-iemma } \\ \text { Engineering Optimization }\end{array} \\ \text { Page } 27 \text { of } 42 & & \end{array}$}

Engineering Optimization

Table 6. Optimized parameters for sound matching using variables set no. 2 .

\begin{tabular}{lccc}
\hline Desing/procedural variables & & target no.1 & target no.2 \\
\hline fuselage angle of attack, deg & $\alpha$ & 4.43 & 3.34 \\
slope angle, deg & $\gamma$ & 5.00 & 4.77 \\
airspeed, m/s & $U_{\infty}$ & 110.00 & 85.00 \\
flap deflection angle, deg & $\delta$ & 20.16 & 40.00 \\
flap span (as a ratio of wing span) & $l_{f} / l_{w}$ & 0.40 & 0.80 \\
flap chord (as a ratio of wing chord) & $c_{f} / c_{w}$ & 0.70 & 0.32 \\
shaft rpm & $n_{s}$ & 1,282 & 1,063 \\
number of fan blades & $n_{b}$ & 33 & 18 \\
fan diameter, m & $d_{f}$ & 2.19 & 2.19 \\
mass flow rate (engine), kg/s & $m_{1}$ & 101.355 & 100.00 \\
jet nozzle diameter (primary), m & $d_{1}$ & 0.20 & 0.23 \\
jets area ratio & $A_{2} / A_{1}$ & 4.13 & 2.87 \\
jet speed (primary), m/s & $u_{1}$ & 249.32 & 236.87 \\
jets speed ratio & $u_{2} / u_{1}$ & 0.34 & 0.37 \\
span, m & $l_{w}$ & 24.06 & 40.00 \\
root chord, m & $c_{w, r}$ & 6.25 & 6.00 \\
tip chord, m & $c_{w, t}$ & 1.04 & 1.00 \\
root built-in angle of attack, deg & $\alpha_{0, r}$ & 5.18 & 6.47 \\
tip built-in angle of attack, deg & $\alpha_{0, t}$ & 7.78 & 7.21 \\
sweep angle, deg & $\delta_{w}$ & 11.52 & 12.10 \\
\hline objective, dB & $\Delta_{p}$ & 2.50 & 2.09 \\
\hline
\end{tabular}

URL: http:/mc.manuscriptcentral.com/geno Email: A.B.Templeman@liverpool.ac.uk 


\section{Figures captions}

Figure 1: Target spectrograms no. 1 and 2. Medium-range, twin-engines aircraft during approach.

Figure 2: Test functions.

Figure 3: $L^{p}$-norm of the absolute value of the difference between the functions in Figure 2.

Figure 4: Target sound no. 1: Comparison between reference and target spectrum (a) 14 sec. prior flyover, (b) at flyover and (c) 14 sec. after flyover.

Figure 5: Target sound no. 2: Comparison between reference and target spectrum (a) 14 sec. prior flyover, (b) at flyover and (c) 14 sec. after flyover.

Figure 6: Variables set no. 1, target sound no. 1: comparison between final and target spectrum (a) 14 sec. prior flyover, (b) at flyover and (c) 14 sec. after flyover.

Figure 7: Variables set no. 1, target sound no. 2: comparison between final and target spectrum (a) 14 sec. prior flyover, (b) at flyover and (c) 14 sec. after flyover.

Figure 8: Variables set no. 1, target sound no. 2: parametric analysis for the final configuration: sounds difference vs. flap deflection.

Figure 9: Variables set no. 1, target sound no. 2: parametric analysis for the final configuration: sounds difference vs. shaft rpm.

Figure 10: Comparison between vector solutions obtained using targets no. 1 and no. 2, for the first set of variables.

Figure 11: Variables set no. 2, target sound no. 1: comparison between final and target spectrum (a) $14 \mathrm{sec}$. prior flyover, (b) at flyover and (c) 14 sec. after flyover.

Figure 12: Variables set no. 2, target sound no. 2: comparison between final and target spectrum (a) 14 sec. prior flyover, (b) at flyover and (c) 14 sec. after flyover.

Figure 13: Comparison between vector solutions obtained using targets no. 1 and no. 2, for the second set of variables.

Figure 14: Link between flight mechanics, propulsion, and noise predictors ( $M=$ flight Mach no., $C_{L}=$ lift coef., $C_{D}=$ drag coef., $C_{M}=$ moment coef.). 


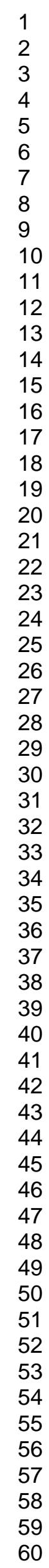

$174 \times 73 \mathrm{~mm}(150 \times 150 \mathrm{DPI})$

URL: http:/mc.manuscriptcentral.com/geno Email: A.B.Templeman@liverpool.ac.uk 


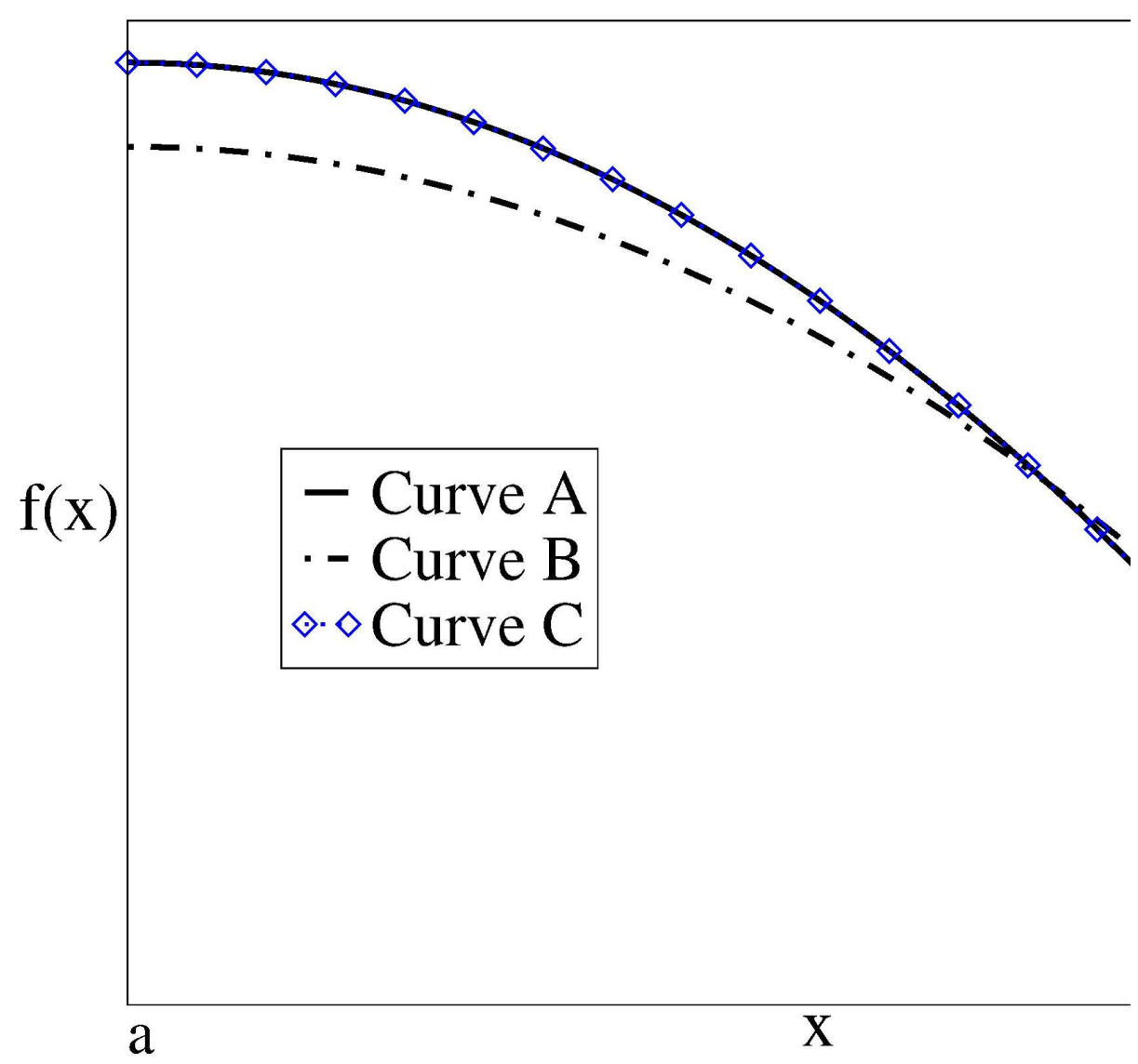

$215 \times 279 \mathrm{~mm}(600 \times 600 \mathrm{DPI})$ 
Page 31 of 42

Engineering Optimization

$$
\begin{aligned}
& 1 \\
& 2 \\
& 3 \\
& 4 \\
& 5 \\
& 6 \\
& 7 \\
& 8 \\
& 9 \\
& 10 \\
& 11 \\
& 12 \\
& 13 \\
& 14 \\
& 15 \\
& 16 \\
& 17 \\
& 18 \\
& 19 \\
& 20 \\
& 21 \\
& 22 \\
& 23 \\
& 24 \\
& 25 \\
& 26 \\
& 27 \\
& 28 \\
& 29 \\
& 30 \\
& 31 \\
& 32 \\
& 33 \\
& 34 \\
& 35 \\
& 36 \\
& 37 \\
& 38 \\
& 39 \\
& 40 \\
& 41 \\
& 42 \\
& 43 \\
& 44 \\
& 45 \\
& 46 \\
& 47 \\
& 48 \\
& 49 \\
& 50 \\
& 51 \\
& 52 \\
& 53 \\
& 5 \\
& \hline
\end{aligned}
$$

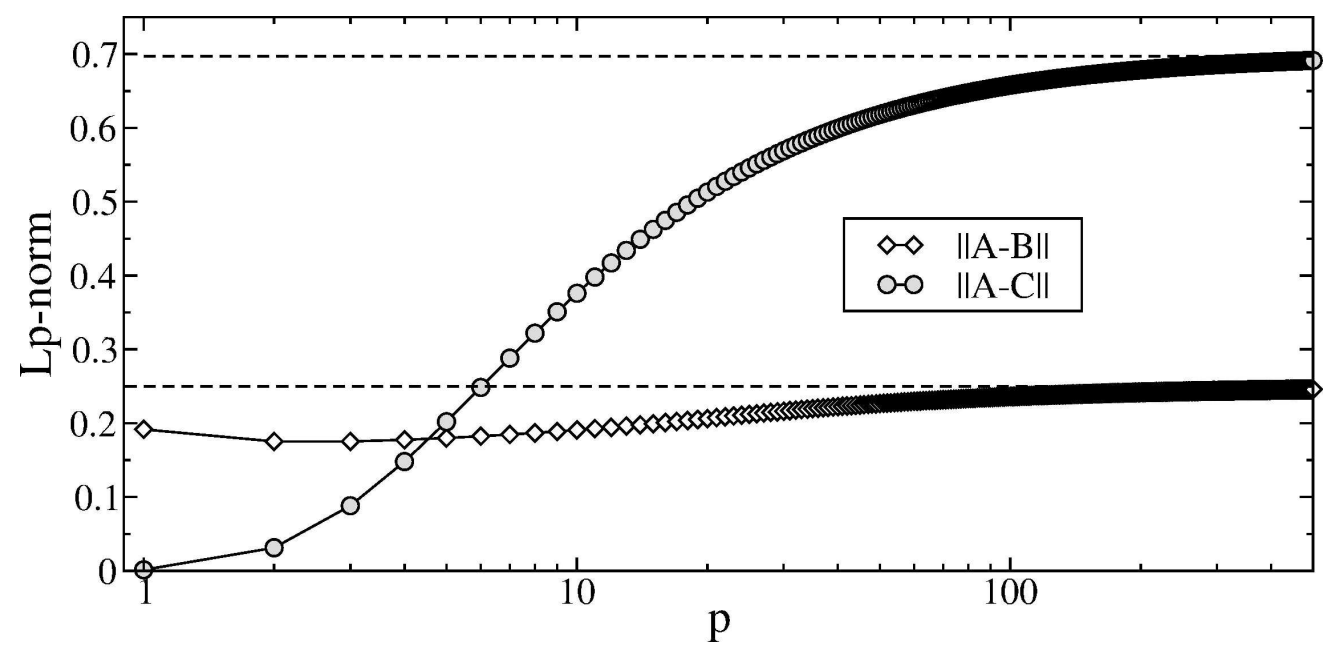

$193 \times 92 \mathrm{~mm}(600 \times 600 \mathrm{DPI})$

URL: http:/mc.manuscriptcentral.com/geno Email: A.B.Templeman@liverpool.ac.uk 


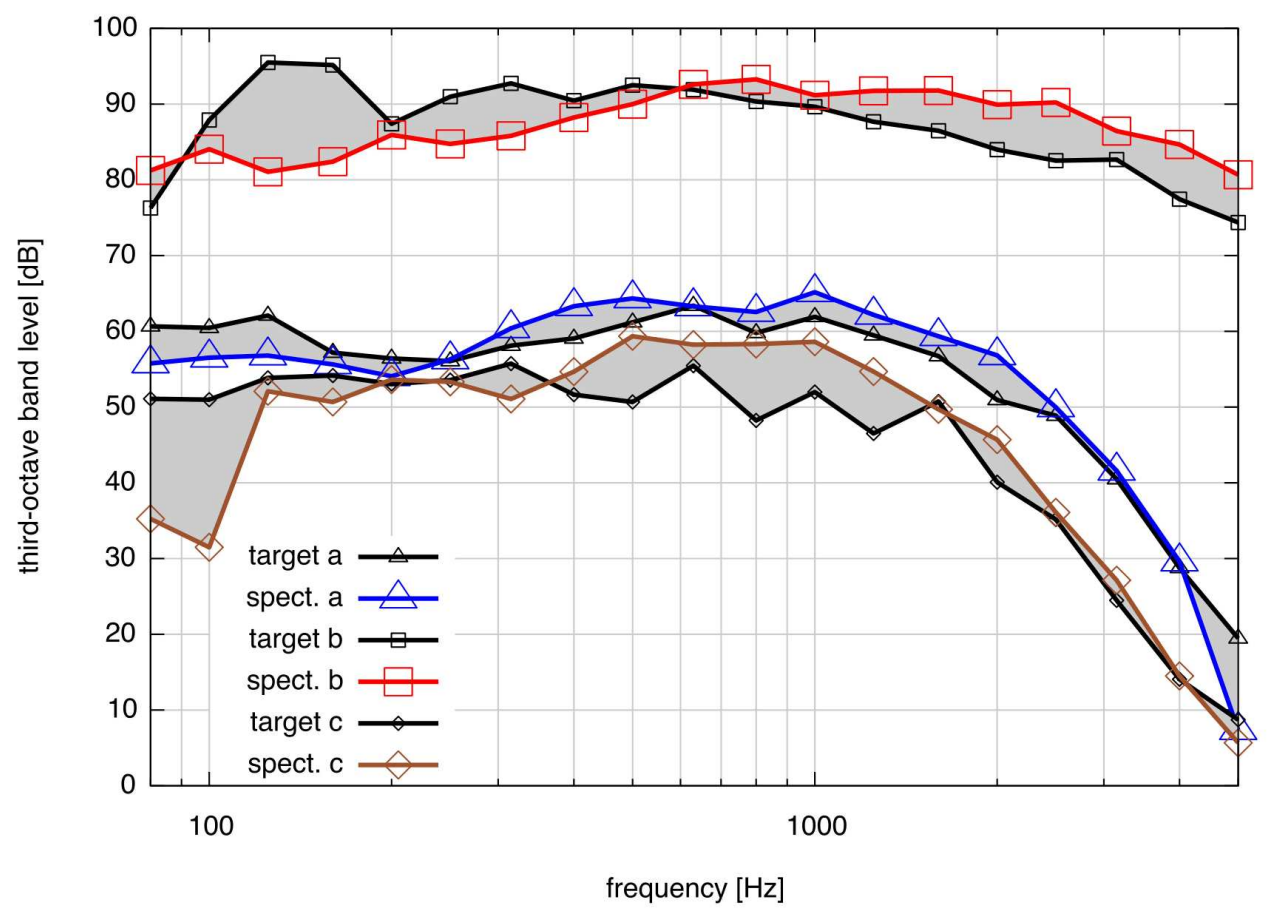

$298 \times 209 \mathrm{~mm}(600 \times 600 \mathrm{DPI})$ 


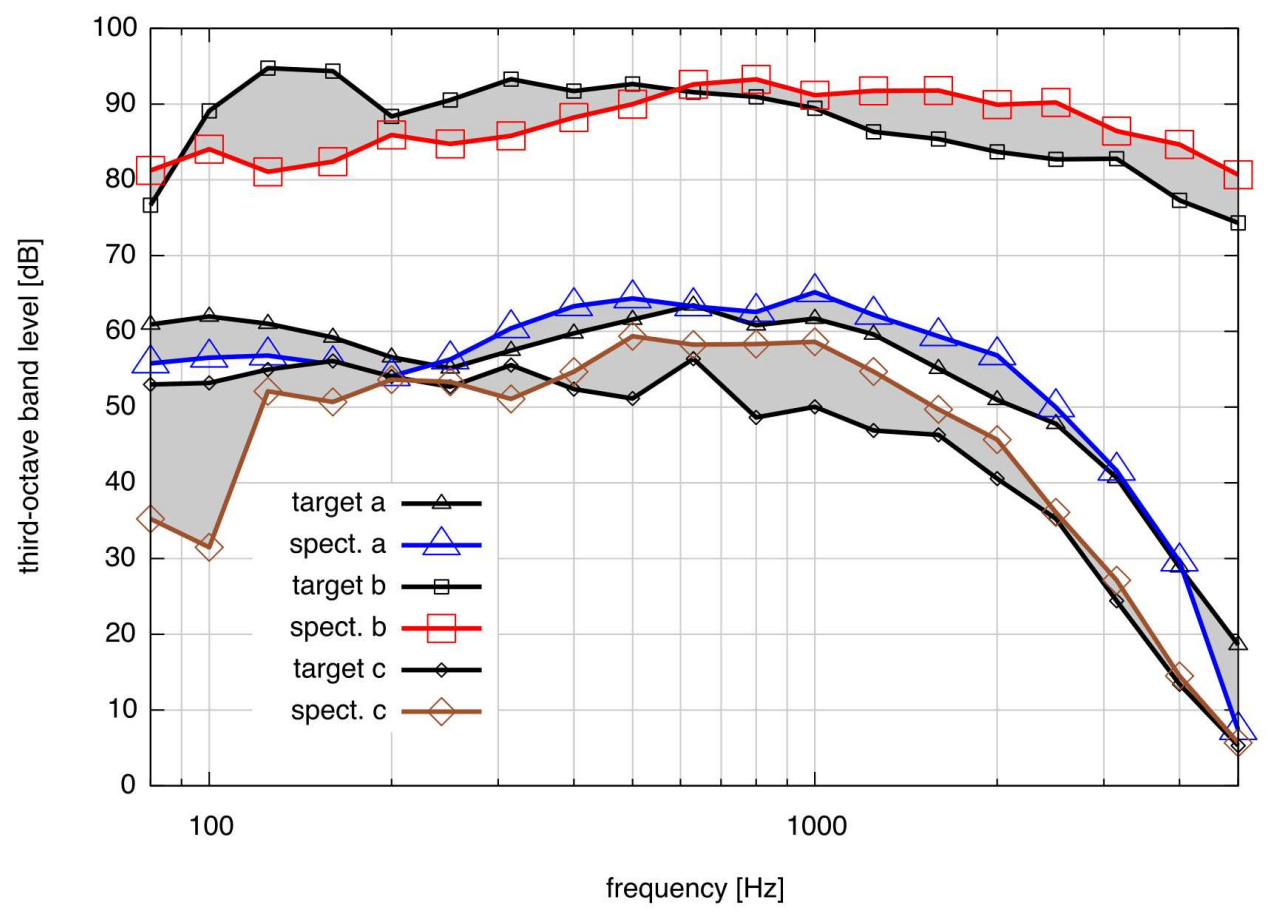

$298 \times 209 \mathrm{~mm}(600 \times 600$ DPI $)$ 


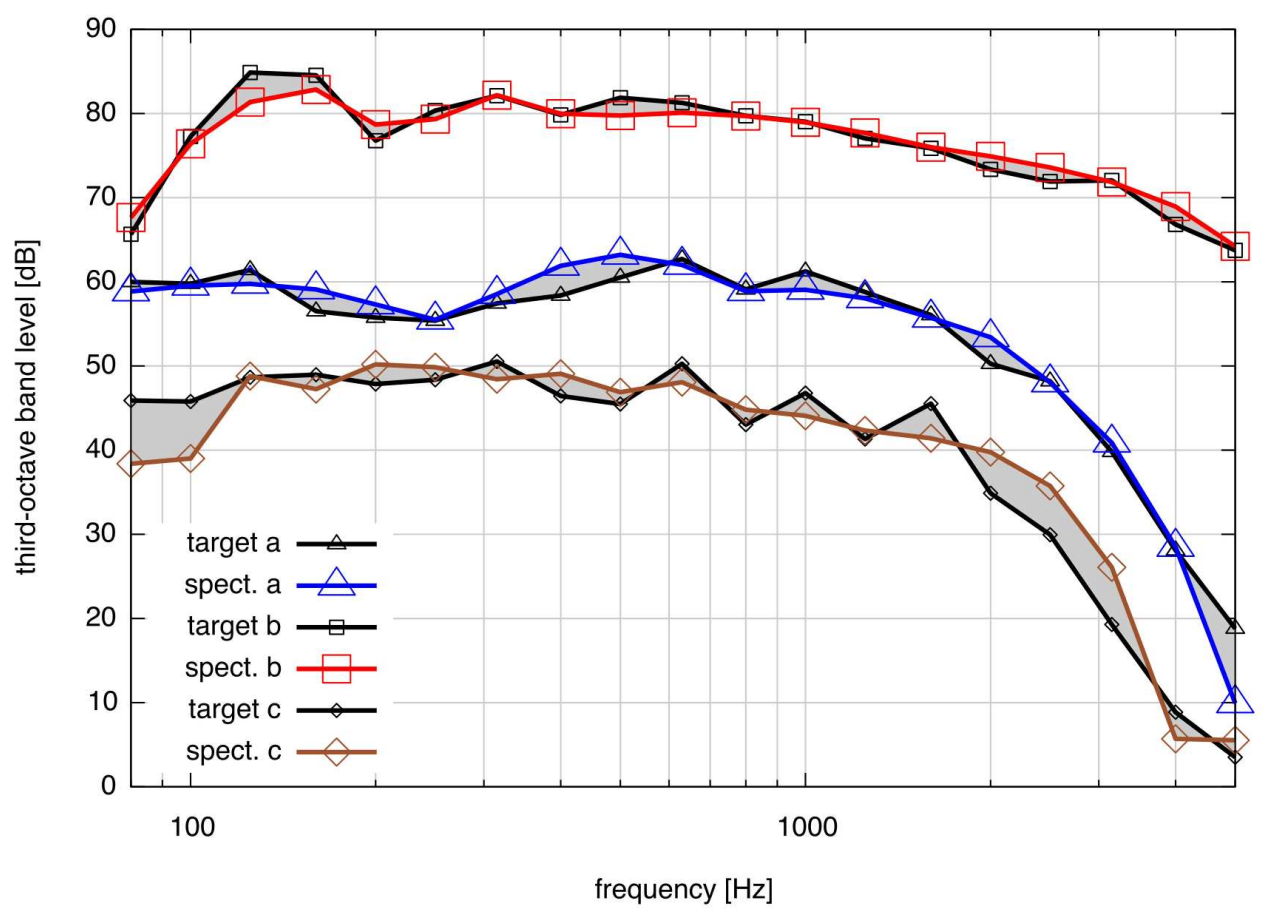

$298 \times 209 \mathrm{~mm}(600 \times 600 \mathrm{DPI})$

URL: http:/mc.manuscriptcentral.com/geno Email: A.B.Templeman@liverpool.ac.uk 


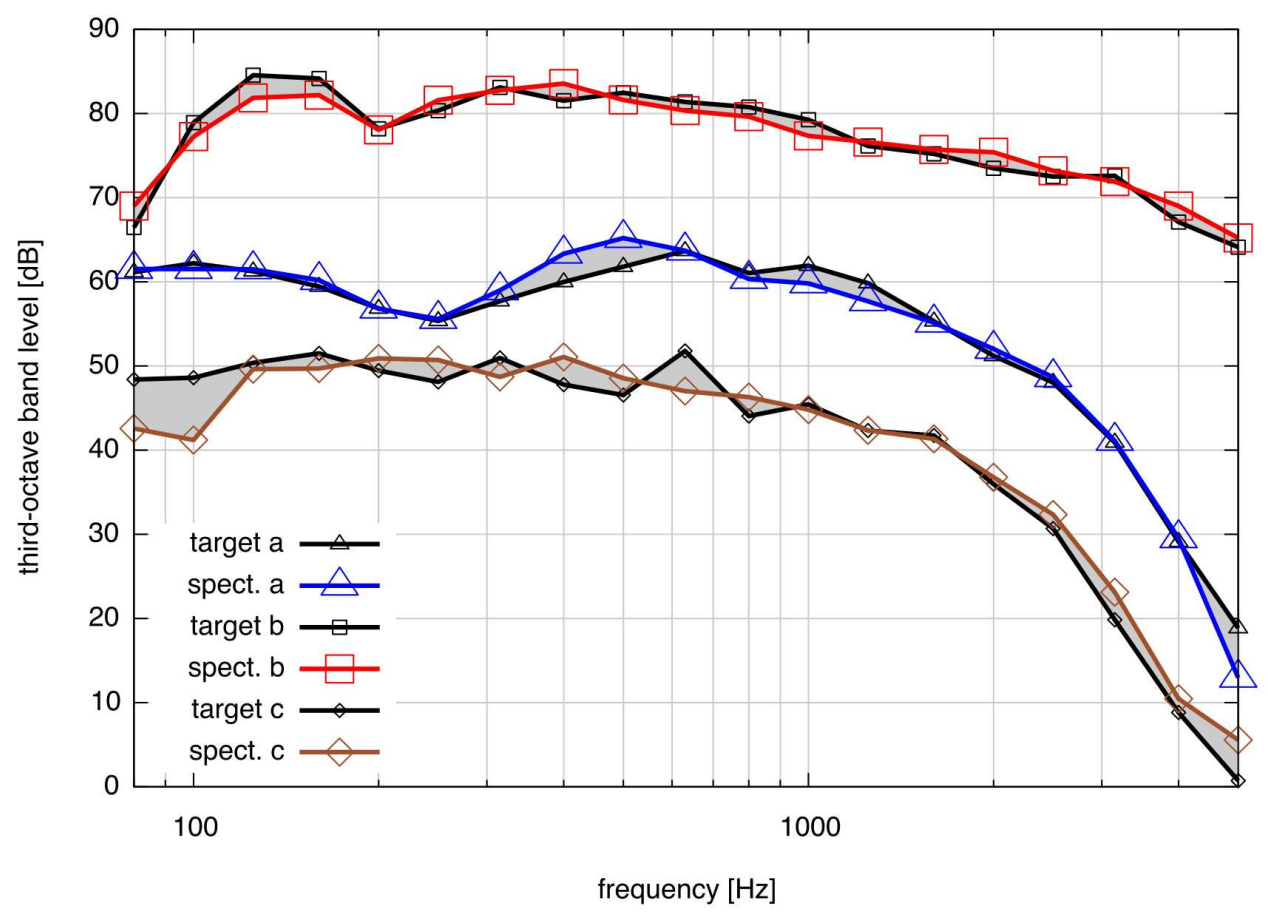

$298 \times 209 \mathrm{~mm}(600 \times 600$ DPI $)$ 


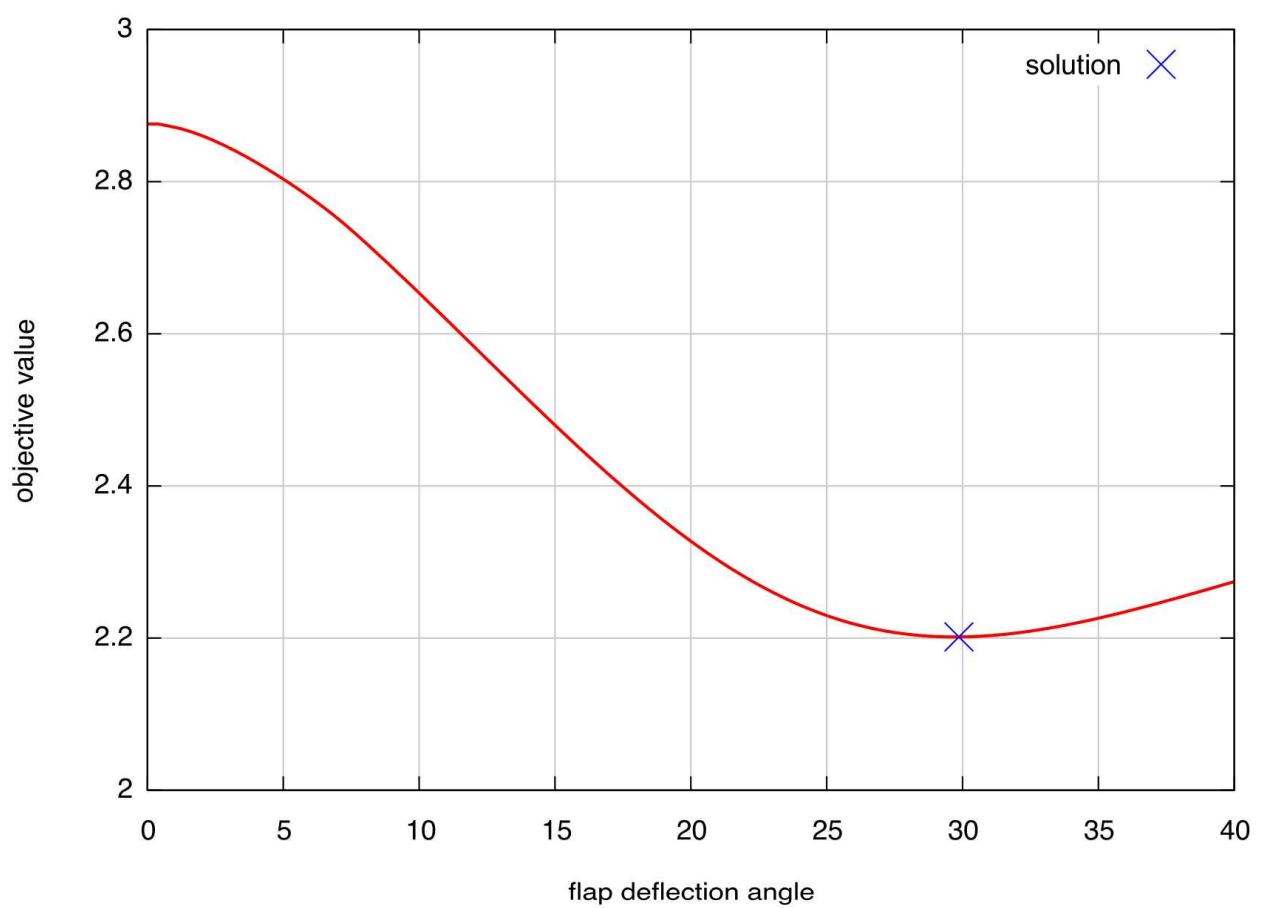

$298 \times 209 m m(600 \times 600$ DPI $)$

1

2

3

4

5

6

9

10

11

12

13

14

16

17

18

19

20

21

23

24

25

26

27

28

34

35

36

37

38

39

40

41

42

43

44

45

46

47

48

49

50

51

52

53

54

55

56

57

58

59

60

URL: http:/mc.manuscriptcentral.com/geno Email: A.B.Templeman@liverpool.ac.uk 


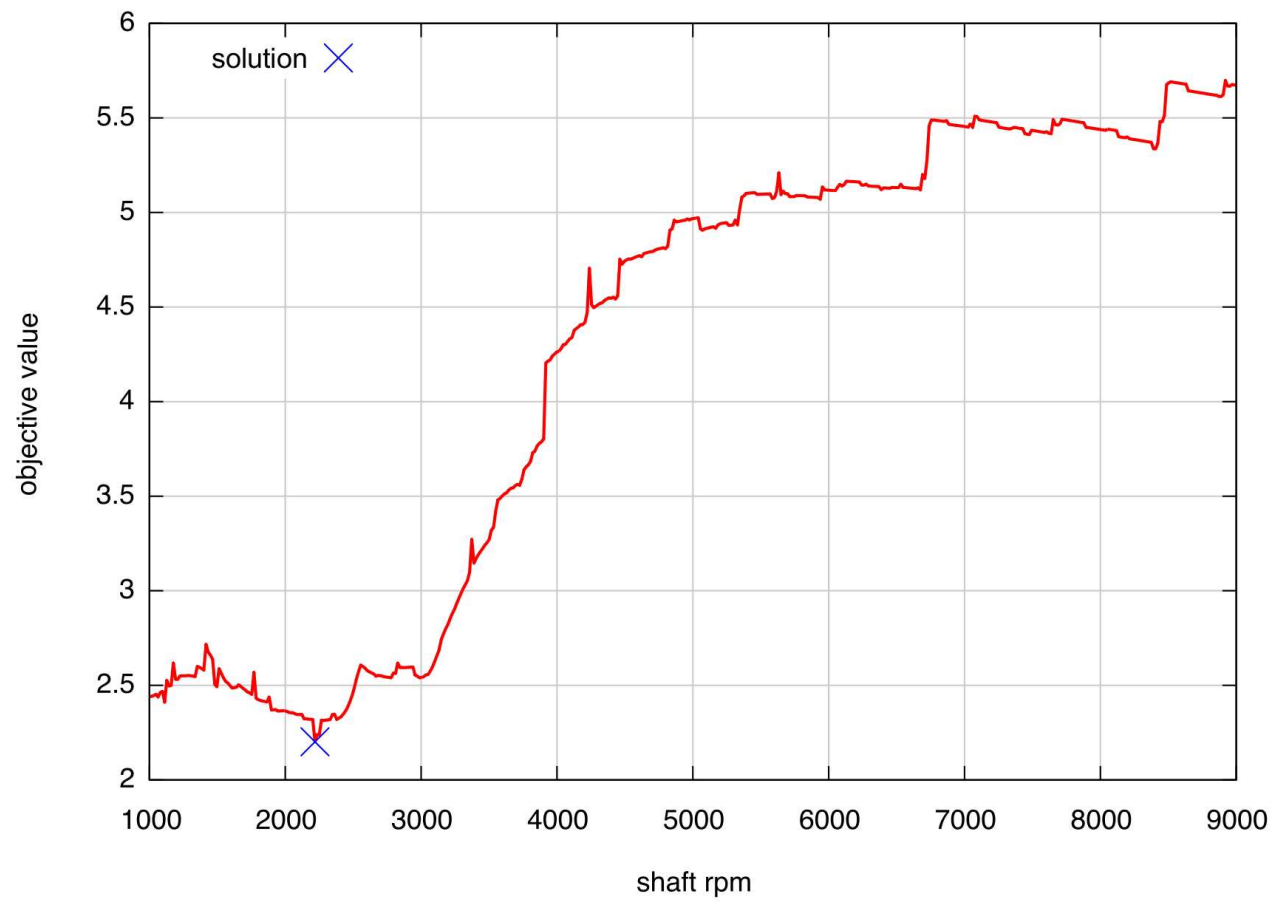

$298 \times 209 \mathrm{~mm}(600 \times 600$ DPI $)$ 


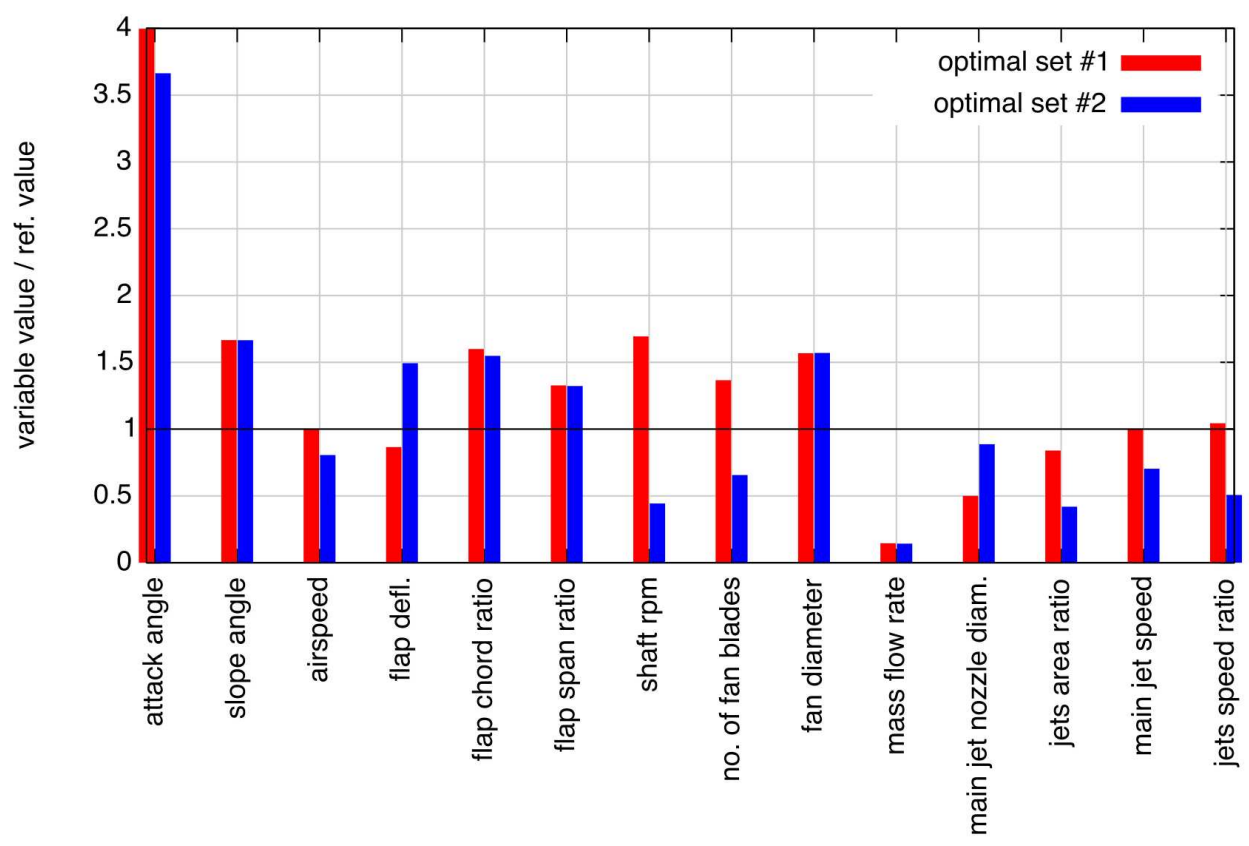

$298 \times 209 m m(600 \times 600$ DPI $)$

34

35

36

37

38

39

40

41

42

43

44

45

46

47

48

49

50

51

52

53

54

55

56

57

58

59

60

URL: http:/mc.manuscriptcentral.com/geno Email: A.B.Templeman@liverpool.ac.uk 


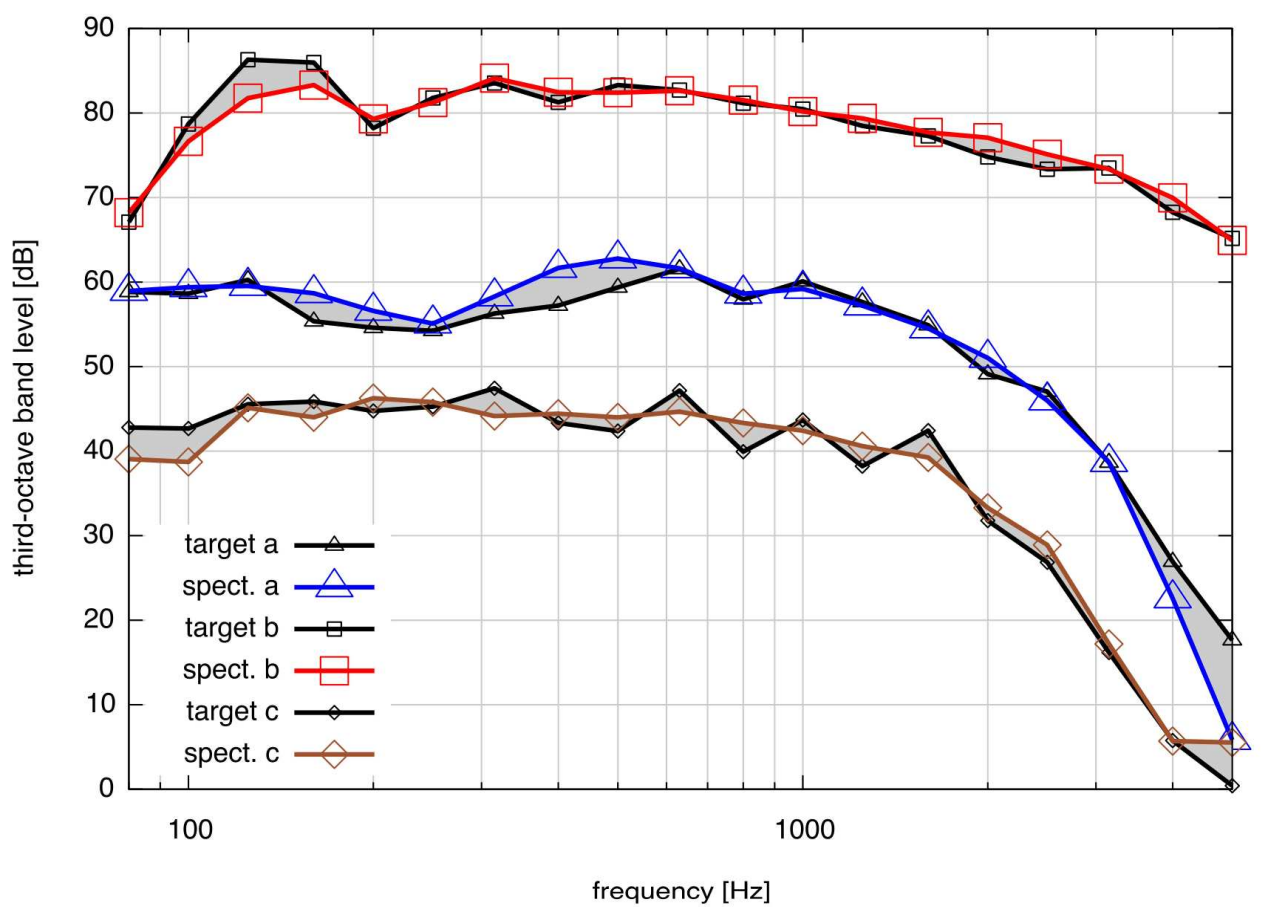

$298 \times 209 \mathrm{~mm}(600 \times 600$ DPI $)$ 


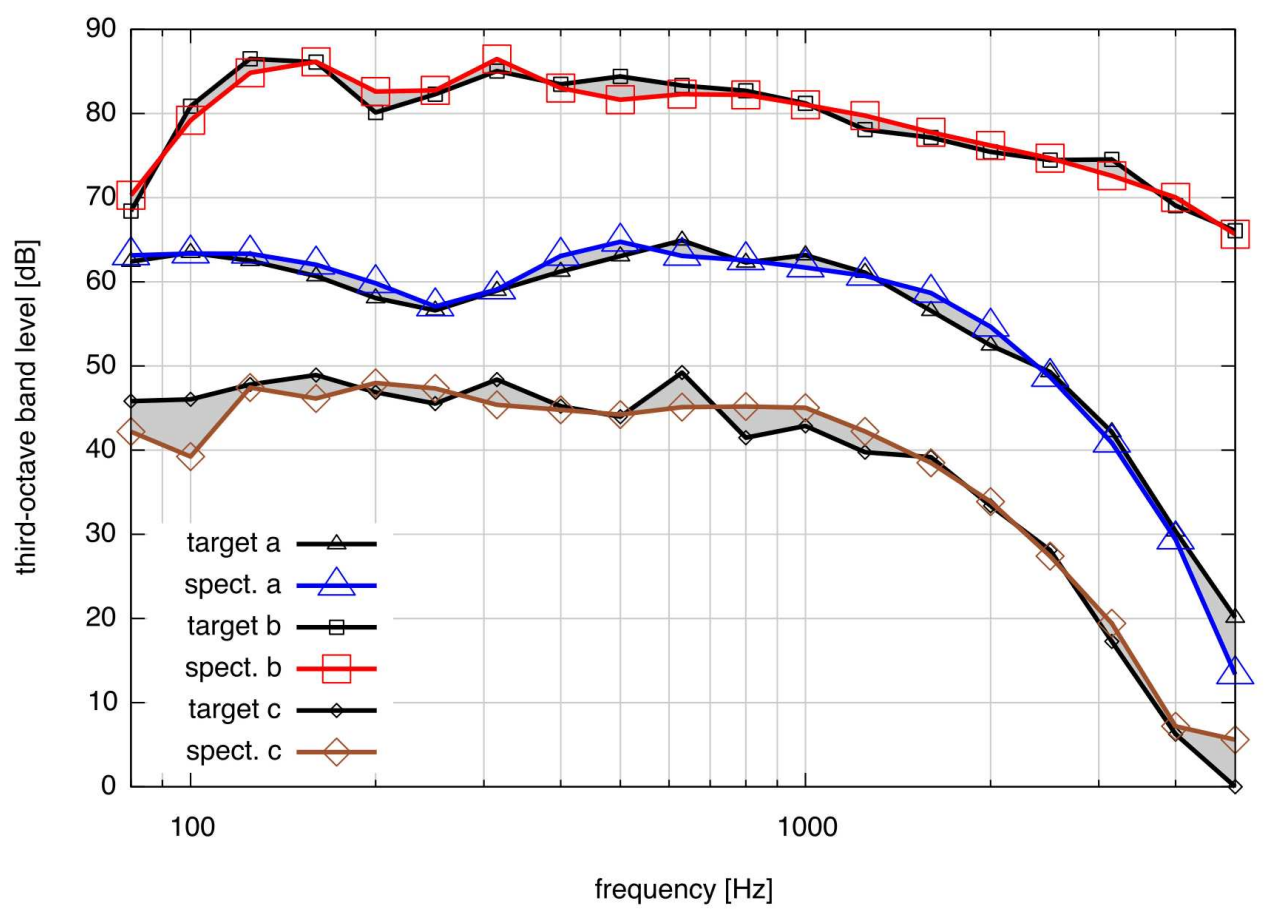

$298 \times 209 \mathrm{~mm}(600 \times 600 \mathrm{DPI})$

URL: http:/mc.manuscriptcentral.com/geno Email: A.B.Templeman@liverpool.ac.uk 


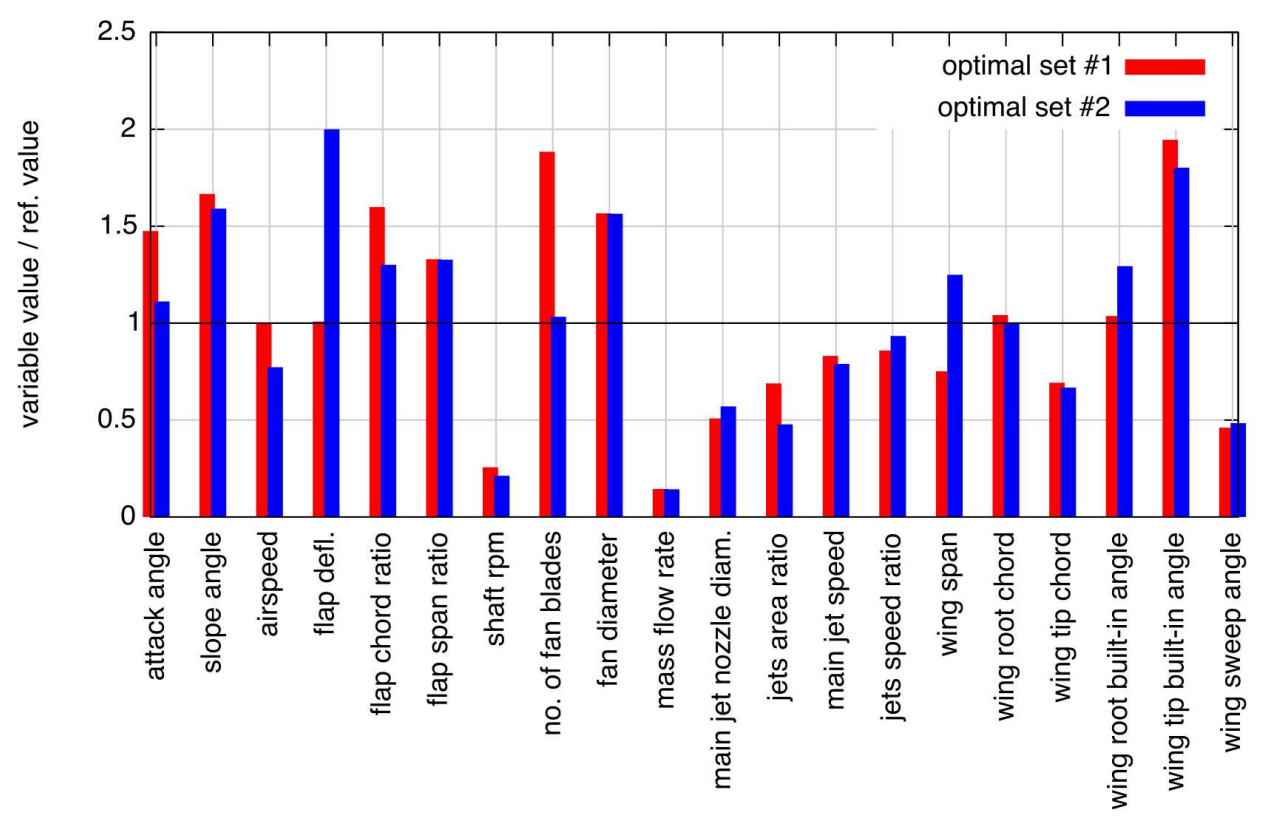

$298 \times 209 \mathrm{~mm}(600 \times 600 \mathrm{DPI})$ 

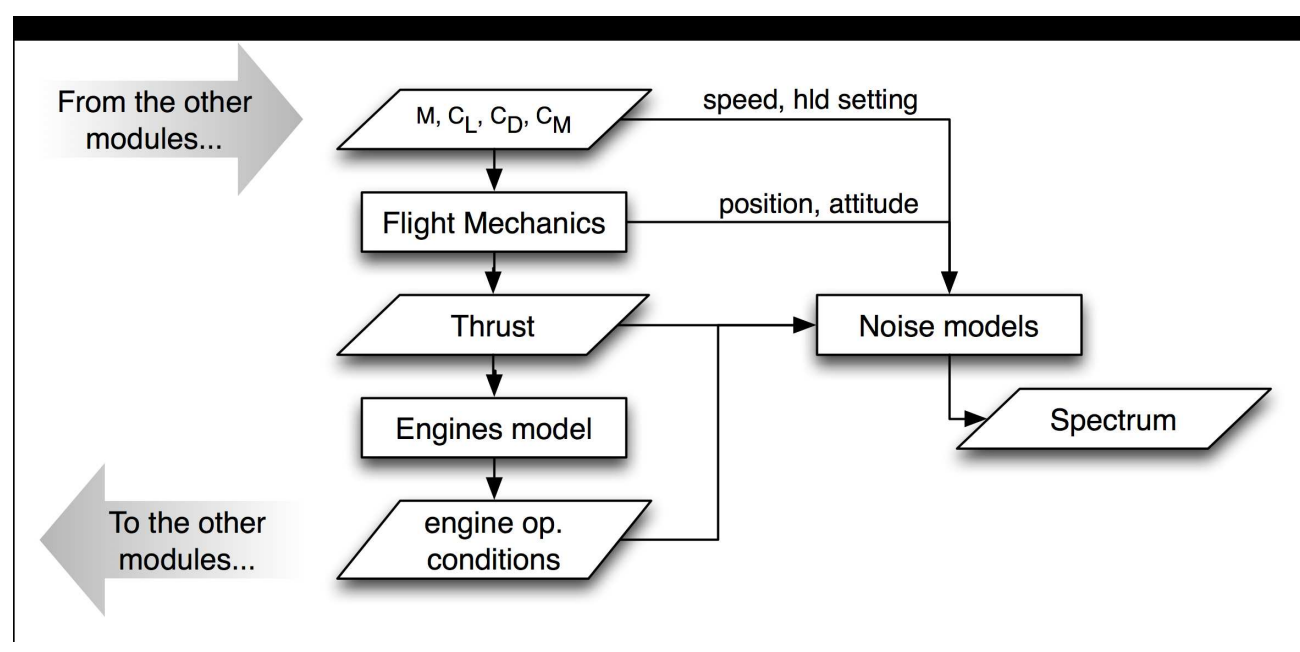

$200 \times 96 \mathrm{~mm}(300 \times 300 \mathrm{DPI})$ 